\title{
The complete genome sequence of Moorella thermoacetica (f. Clostridium thermoaceticum)
}

\author{
Elizabeth Pierce, ${ }^{1}$ Gary Xie, ${ }^{2,3}$ Ravi D. Barabote, ${ }^{2,3}$ \\ Elizabeth Saunders, ${ }^{2,3}$ Cliff S. Han, ${ }^{2,3}$ \\ John C. Detter, ${ }^{2,3}$ Paul Richardson, ${ }^{2,4}$ \\ Thomas S. Brettin, ${ }^{2,3}$ Amaresh Das, ${ }^{5}$ \\ Lars G. Ljungdahl ${ }^{5}$ and Stephen W. Ragsdale ${ }^{1 *}$ \\ ${ }^{1}$ Department of Biological Chemistry, University of \\ Michigan, Ann Arbor, MI, USA. \\ ${ }^{2}$ Los Alamos National Laboratory, Bioscience Division, \\ Los Alamos, NM, USA. \\ ${ }^{3}$ Department of Energy Joint Genome Institute, \\ Walnut Creek, CA, USA. \\ ${ }^{4}$ Lawrence Berkeley National Laboratory, Berkeley, CA, \\ USA. \\ ${ }^{5}$ Department of Biochemistry and Molecular Biology, \\ University of Georgia, Athens, GA, USA.
}

\section{Summary}

This paper describes the genome sequence of Moorella thermoacetica (f. Clostridium thermoaceticum), which is the model acetogenic bacterium that has been widely used for elucidating the Wood-Ljungdahl pathway of $\mathrm{CO}$ and $\mathrm{CO}_{2}$ fixation. This pathway, which is also known as the reductive acetyl-CoA pathway, allows acetogenic (often called homoacetogenic) bacteria to convert glucose stoichiometrically into $3 \mathrm{~mol}$ of acetate and to grow autotrophically using $\mathrm{H}_{2}$ and $\mathrm{CO}$ as electron donors and $\mathrm{CO}_{2}$ as an electron acceptor. Methanogenic archaea use this pathway in reverse to grow by converting acetate into methane and $\mathrm{CO}_{2}$. Acetogenic bacteria also couple the Wood-Ljungdahl pathway to a variety of other pathways to allow the metabolism of a wide variety of carbon sources and electron donors (sugars, carboxylic acids, alcohols and aromatic compounds) and electron acceptors $\left(\mathrm{CO}_{2}\right.$, nitrate, nitrite, thiosulfate, dimethylsulfoxide and aromatic carboxyl groups). The genome consists of a single circular 2628784 bp chromosome encoding 2615 open reading frames (ORFs), which includes 2523 predicted protein-encoding genes. Of these, 1834 genes $(\mathbf{7 0 . 1 3} \%)$ have been assigned tentative

Received 20 December, 2007; accepted 1 May, 2008. *For correspondence. E-mail sragsdal@umich.edu; Tel. (+1) 734615 4621; Fax (+1) 7347634581. functions, $665(25.43 \%)$ matched genes of unknown function, and the remaining $24(0.92 \%)$ had no database match. A total of $2384(91.17 \%)$ of the ORFs in the M. thermoacetica genome can be grouped in orthologue clusters. This first genome sequence of an acetogenic bacterium provides important information related to how acetogens engage their extreme metabolic diversity by switching among different carbon substrates and electron donors/acceptors and how they conserve energy by anaerobic respiration. Our genome analysis indicates that the key genetic trait for homoacetogenesis is the core acs gene cluster of the Wood-Ljungdahl pathway.

\section{Introduction}

Here we report the first complete genome sequence of an acetogenic bacterium. Acetogens are obligately anaerobic bacteria that use a mechanism of anaerobic $\mathrm{CO}$ and $\mathrm{CO}_{2}$ fixation, called the reductive acetyl-CoA or the Wood-Ljungdahl pathway as their main mechanism for energy conservation and for synthesis of acetyl-CoA and cell carbon from $\mathrm{CO}_{2}$ (Drake et al., 1994). Other terms to describe an organism using this type of metabolism are 'homoacetogen' and ' $\mathrm{CO}_{2}$-reducing acetogen'. We determined the genome sequence of Moorella thermoacetica, originally named Clostridium thermoaceticum, which has been the model acetogen since its isolation in 1942 (Fontaine et al., 1942) for elucidating the WoodLjungdahl pathway. As discussed below, this pathway is found in a broad range of phylogenetic classes, and is used in both the oxidative and reductive directions. Besides being used for energy production and autotrophic carbon assimilation in acetogens (Ljungdahl, 1994; Ragsdale, 1997; Drake et al., 2002), the Wood-Ljungdahl pathway is used for acetate catabolism by sulfatereducing bacteria (Schauder et al., 1988; Spormann and Thauer, 1988) and aceticlastic methanogens (Ferry, 1999) and for $\mathrm{CO}_{2}$ fixation by hydrogenotrophic methanogens (Stupperich et al., 1983; Ladapo and Whitman, 1990).

As early as 1932, organisms were discovered that could convert $\mathrm{H}_{2}$ and $\mathrm{CO}_{2}$ into acetic acid (Fischer et al., 1932). In 1936, Wieringa reported the first acetogenic bacterium, Clostridium aceticum (Wieringa, 1936; 1940), which was reisolated in 1981 (Braun et al., 1981). Moorella thermoacetica (Collins et al., 1994), a 
clostridium in the Thermoanaerobacteriaceae family, attracted wide interest when it was isolated because of its unusual ability to convert glucose almost stoichiometrically to $3 \mathrm{~mol}$ of acetic acid (Fontaine et al., 1942). It took many years to uncover the biochemical reactions responsible for this homoacetogenic pathway. The novelty of this pathway was recognized with the discovery that growth of $M$. thermoacetica on glucose involves incorporation of two molecules of $\mathrm{CO}_{2}$ directly into acetic acid (Barker and Kamen, 1945; Wood, 1952). The isolation of Acetobacterium woodii in 1977 and the description of methods to isolate organisms that can grow on $\mathrm{H}_{2}$ and $\mathrm{CO}_{2}$ (Balch et al., 1977) led to the isolation of many acetogens that can grow autotrophically, and in 1983 M. thermoacetica was shown to grow on $\mathrm{H}_{2} / \mathrm{CO}_{2}$ (Kerby and Zeikus, 1983). The identification of a hydrogenase in 1982 provided a biochemical basis for autotrophic growth of acetogens on hydrogen (Drake, 1982). Subsequently, acetogens have been shown to use a wide variety of carbon sources and electron donors and acceptors. Moorella thermoacetica is a versatile heterotroph, growing on sugars, two-carbon compounds (glyoxylate, glycolate and oxalate), lactate, pyruvate, short-chain fatty acids and methoxylated aromatic compounds. Besides $\mathrm{CO}_{2}$, electron acceptors include nitrate, nitrite, thiosulfate and dimethylsulfoxide.

Acetogenic bacteria play an important role in the global carbon cycle, producing over $10^{12} \mathrm{~kg}$ (10 billion US tons) of acetic acid on a huge scale annually (Wood and Ljungdahl, 1991; Drake et al., 1994), which dwarfs the total output of acetate (an important chemical feedstock) by the world's chemical industry $\left(\sim 10^{10} \mathrm{~kg}_{\text {year }}{ }^{-1}\right)$. While most acetogens like $M$. thermoacetica are in the phylum Firmicutes, acetogens include Spirochaetes (Leadbetter et al., 1999; Salmassi and Leadbetter, 2003), Deltaproteobacteria like Desulfotignum phosphitoxidans (Schink et al., 2002), and Acidobacteria like Holophaga foetida (Liesack et al., 1994). Important in the biology of the soil, lakes and oceans, acetogens have been isolated from diverse environments, including the GI tracts of animals and termites (Breznak, 1994; Mackie and Bryant, 1994), rice paddy soils (Rosencrantz et al., 1999), hypersaline waters (Ollivier et al., 1994), surface soils (Peters and Conrad, 1995; Kusel et al., 1999) and deep subsurface sediments (Liu and Suflita, 1993). Like methanogens, acetogens act as a $\mathrm{H}_{2}$ sink, depleting $\mathrm{H}_{2}$ that is generated in anaerobic environments during the natural biodegradation of organic compounds. As the build-up of $\mathrm{H}_{2}$ inhibits biodegradation by creating an unfavourable thermodynamic equilibrium, acetogens enhance biodegradative capacity by coupling the oxidation of hydrogen gas to the reduction of $\mathrm{CO}_{2}$ to acetate. Acetogens also have been found in a methanogenic mixed population from an army ammunition manufacturing plant waste water treatment facility (Adrian and Arnett, 2004) and a dechlorinating community that has been enriched for bioremediation (Macbeth et al., 2004).

For organisms that house acetogens in their digestive systems, like humans, termites and ruminants (Greening and Leedle, 1989; Tholen and Brune, 1999; Chassard and Bernalier-Donadille, 2006), the acetate generated by microbial metabolism is a beneficial nutrient for the host and for other microbes within the community. In these ecosystems, acetogens can compete directly with hydrogenotrophic methanogenic archaea, or interact syntrophically with acetotrophic methanogens that use $\mathrm{H}_{2}$ and $\mathrm{CO}_{2}$ to produce methane (Chassard and Bernalier-Donadille, 2006). Organisms containing the acs gene cluster are also enriched in the marine and terrestrial vertebrate and invertebrate gut biomes (Gill et al., 2006; Warnecke et al., 2007). In the termite gut, acetogens are the dominant hydrogen sinks (Pester and Brune, 2007), and it has been proposed that acetate is the major energy source for the termite (Odelson and Breznak, 1983). However, methanogens are the dominant hydrogenotrophs in many environments as methanogens have a lower threshold for $\mathrm{H}_{2}$ than acetogens (Le Van et al., 1998) and as the energy yield from the conversion of $\mathrm{CO}_{2}$ and $\mathrm{H}_{2}$ to methane is greater than that for conversion to acetate (Schink, 1997). Under such conditions, acetogens must often resort to other metabolic pathways for growth and, thus, have a highly diverse metabolic menu that comprises the biodegradation products of most natural polymers like cellulose and lignin, including sugars, alcohols, organic acids and aldehydes, aromatic compounds and inorganic gases like $\mathrm{CO}, \mathrm{H}_{2}$ and $\mathrm{CO}_{2}$. They also can use a variety of electron acceptors, e.g. $\mathrm{CO}_{2}$, nitrate, dimethylsulfoxide, fumarate and protons. The $M$. thermoacetica genome sequence described here provides important information related to how acetogens engage this extreme metabolic diversity and how they switch with such facility among different carbon substrates and electron donors and acceptors.

\section{Results}

\section{General genome features}

The major features of the $M$. thermoacetica genome are listed in Table 1 and shown in Fig. S1. The genome consists of a single circular 2628784 bp chromosome that has a GC content of $56 \%$ (Fig. S1). Base pair one of the chromosome was assigned within the putative origin of replication. The genome contains 51 tRNAs, three rRNAs (5S, 16S and 23S) and 38 other RNAs predicted by the Rfam. Analysis of $16 S$ rRNA sequences confirmed that M. thermoacetica belongs to the phylum Clostridia (Fig. 1) and to the class Thermoanaerobacteriaceae. Figure 1 also highlights the known homoacetogenic microbes, revealing the wide distribution of phylogenetic classes in 
Table 1. General features of the M. thermoacetica genome.

\begin{tabular}{ll} 
Genome size (base pairs) & 2628784 \\
G+C content & 0.56 \\
Open reading frames & 2615 \\
Predicted protein encoding sequences & 2523 \\
Predicted sequences encoding RNA genes & 92 \\
Coding density & $97.90 \%$ \\
rRNA & 3 \\
tRNA & 51 \\
Genes with function prediction (percentage) & $1834(71.17 \%)$ \\
Number of genes in COG (percentage) & $2008(76.79 \%)$ \\
Number of genes in Pfam (percentage) & $2001(76.52 \%)$ \\
Genes encoding signal peptides (percentage) & $159(6.08 \%)$ \\
Genes encoding transmembrane proteins & $570(21.8 \%)$ \\
(percentage) & \\
Genes with orthologues (percentage) & $2326(90.26 \%)$ \\
Genes with paralogues (percentage) & $1361(52.81 \%)$ \\
\hline
\end{tabular}

which this trait appears, clearly indicating that acetogenesis is a metabolic, not a phylogenetic trait. Besides the bacteria shown in Fig. 1, which are related to M. thermoacetica, the Wood-Ljungdahl pathway is also found in archaea. On the other hand, homoacetogenesis is a rare occurrence within a particular phylum. For example, two relatives of $M$. thermoacetica in the Thermoanaerobacteriaceae family whose genomes have been sequenced, Thermoanaerobacter tengcongensis (Bao et al., 2002) and Thermoanaerobacter ethanolicus (draft sequence available at JGI), can also grow anaerobically on several mono- and disaccharides and starch (Wiegel and Ljungdahl, 1981); however, among these three strains, only $M$. thermoacetica is homoacetogenic, and only $M$. thermoacetica has acetyl coenzyme A synthase (ACS), a key enzyme in the Wood-Ljungdahl pathway. Fermentation of glucose by $T$. tengcongensis or T. ethanolicus yields ethanol and/or acetate, $1.5-2 \mathrm{~mol}$ of $\mathrm{CO}_{2}$ and small amounts of $\mathrm{H}_{2}$. Thus, the genomic results clearly indicate that the trait of acetogenesis was distributed by horizontal transfer of the core genes of the WoodLjungdahl pathway.

The M. thermoacetica genome contains 2523 predicted protein-encoding genes, of which 1834 (70.13\%) have been assigned tentative functions. Six hundred sixty-five predicted proteins $(25.43 \%)$ matched proteins of unknown function, and the remaining $24(0.92 \%)$ had no database match. A total of 429 paralogous protein families were identified in M. thermoacetica strain ATCC 39073, containing 1307 predicted proteins $(49.98 \%$ of the total). A total of $2384(91.17 \%)$ of the open reading frames (ORFs) in the $M$. thermoacetica genome can be grouped in orthologue clusters. Fifty-eight pseudogenes were identified in the M. thermoacetica genome by the IMG annotation. A complete list of pseudogenes and gene remnants is provided in Table S1. Analysis of these genes in $M$. thermoacetica indicates that 41 out of 58 are redundant genes, with paralogues in the M. thermoacetica genome. The 17 that do not have paralogues encode either putative or hypothetical proteins. These results suggest that elimination of the functions of these redundant genes may be tenuously ascribed to selective pressures.

\section{The Wood-Ljungdahl pathway genes}

Figure 2 shows the genes encoding the key enzymes in the Wood-Ljungdahl pathway of $\mathrm{CO}_{2}$ fixation in which two molecules of $\mathrm{CO}_{2}$ are reduced to a methyl and a carbonyl group, and are joined with coenzyme $\mathrm{A}(\mathrm{CoA})$ to make acetyl-CoA. Acetyl-CoA is then incorporated into cell carbon or converted to acetyl phosphate, whose phosphoryl group is transferred to ADP to generate ATP and acetate, the main growth product of acetogenic bacteria (for reviews see Ljungdahl, 1986; Drake and Daniel, 1997; Ragsdale, 1997). This pathway has been described to consist of an Eastern (blue colouring scheme) and a Western (red) branch (Fig. 2; Ragsdale, 1997).

\section{Genes encoding the Eastern branch of the Wood-Ljungdahl pathway}

The genes encoding enzymes in the Eastern branch of the pathway that are involved in the conversion of $\mathrm{CO}_{2}$ to methyl- $\mathrm{H}_{4}$ folate (Fig. 2) are common to most organisms, though they are expressed at much higher levels in acetogens. As shown in Fig. 3, many of the genes encoding functions of the Eastern branch of the pathway are dispersed on the genome at locations distant from the core genes of the Wood-Ljungdahl pathway, which are involved in converting methyl- $\mathrm{H}_{4}$ folate, $\mathrm{CoA}$ and $\mathrm{CO}_{2}$ to acetyl-CoA. The functional assignments of all these genes (except phosphotransacetylase, below) are backed by biochemical evidence based on protein sequence analysis of well-characterized enzymes.

Conversion of $\mathrm{CO}_{2}$ to formate is catalysed by the wellcharacterized selenocysteine-containing formate dehydrogenase (Li et al., 1966; Andreesen and Ljungdahl, 1973; Yamamoto et al., 1983). Moth_2312 and Moth_2313, which are actually one gene, match the sequence deposited by $\mathrm{Li}$, Ljungdahl and Gollin in GenBank (gi 1658401) as the formate dehydrogenase $\alpha$ subunit. The two ORFs were separated in the original genome annotation because they contain the codon for selenocysteine, a stop codon in most contexts. Moth_2314 matches the sequence of the $\beta$ subunit. In acetogens, formate dehydrogenase catalyses an especially interesting reaction as the reduction of $\mathrm{CO}_{2}$ to formate $\left(E_{0}=-420\right)$ is coupled to the oxidation of $\mathrm{NADPH}$ to $\mathrm{NADP}^{+}\left(E_{0}=-340 \mathrm{mV}\right)$. The M. thermoacetica formate dehydrogenase was the first enzyme shown to contain tungsten (Ljungdahl and Andreesen, 1975). Another 


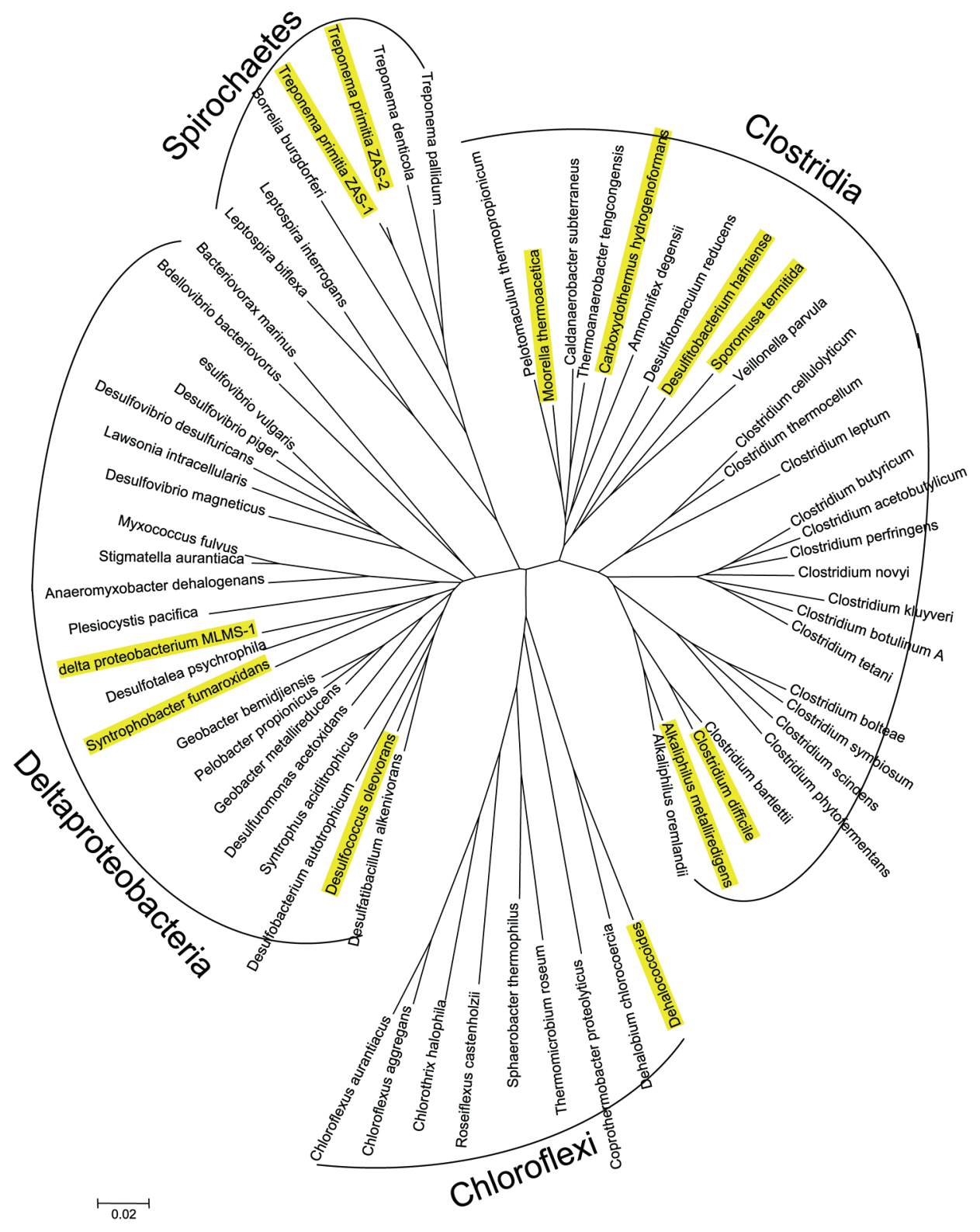

Fig. 1. 16S rRNA-based phylogenetic tree of acetogens and their close neighbours. The tree was derived from 16S rDNA sequence data, and was constructed using the MEGA program neighbour-joining method. Highlighted in yellow are acetogens that have the Wood-Ljungdahl pathway gene clusters listed in Fig. 4.

selenocysteine-containing formate dehydrogenase (Moth_2193), which appears to be part of a formate hydrogen lyase system (Moth_2184-2193), is described below.

The genes encoding 10-formyl- $\mathrm{H}_{4}$ folate synthetase (Moth_0109) and the bifunctional 5,10-methenyl- $\mathrm{H}_{4}$ folate cyclohydrolase/5,10-methylene- $\mathrm{H}_{4}$ folate dehydrogenase (Moth_1516) are dispersed on the genome and distant from the acs gene cluster by at least 300 genes (Fig. 3). In the reaction catalysed by 10 -formyl- $\mathrm{H}_{4}$ folate synthetase, formate undergoes an ATP-dependent condensation with
$\mathrm{H}_{4}$ folate, forming 10-formyl- $\mathrm{H}_{4}$ folate. This enzyme has been purified, characterized and sequenced from a number of sources including M. thermoacetica (Himes and Wilder, 1968; O'Brien et al., 1975; McGuire and Rabinowitz, 1978; Lovell et al., 1988; 1990). In higher organisms, this enzyme exists as one of the activities of a trifunctional $\mathrm{C}_{1}-\mathrm{H}_{4}$ folate synthase (also containing cyclohydrolase and dehydrogenase; Staben and Rabinowitz, 1986; Shannon and Rabinowitz, 1988), whereas the bacterial formyl- $\mathrm{H}_{4}$ folate synthetases are monofunctional and share similar properties (Lovell et al., 1990). While the 


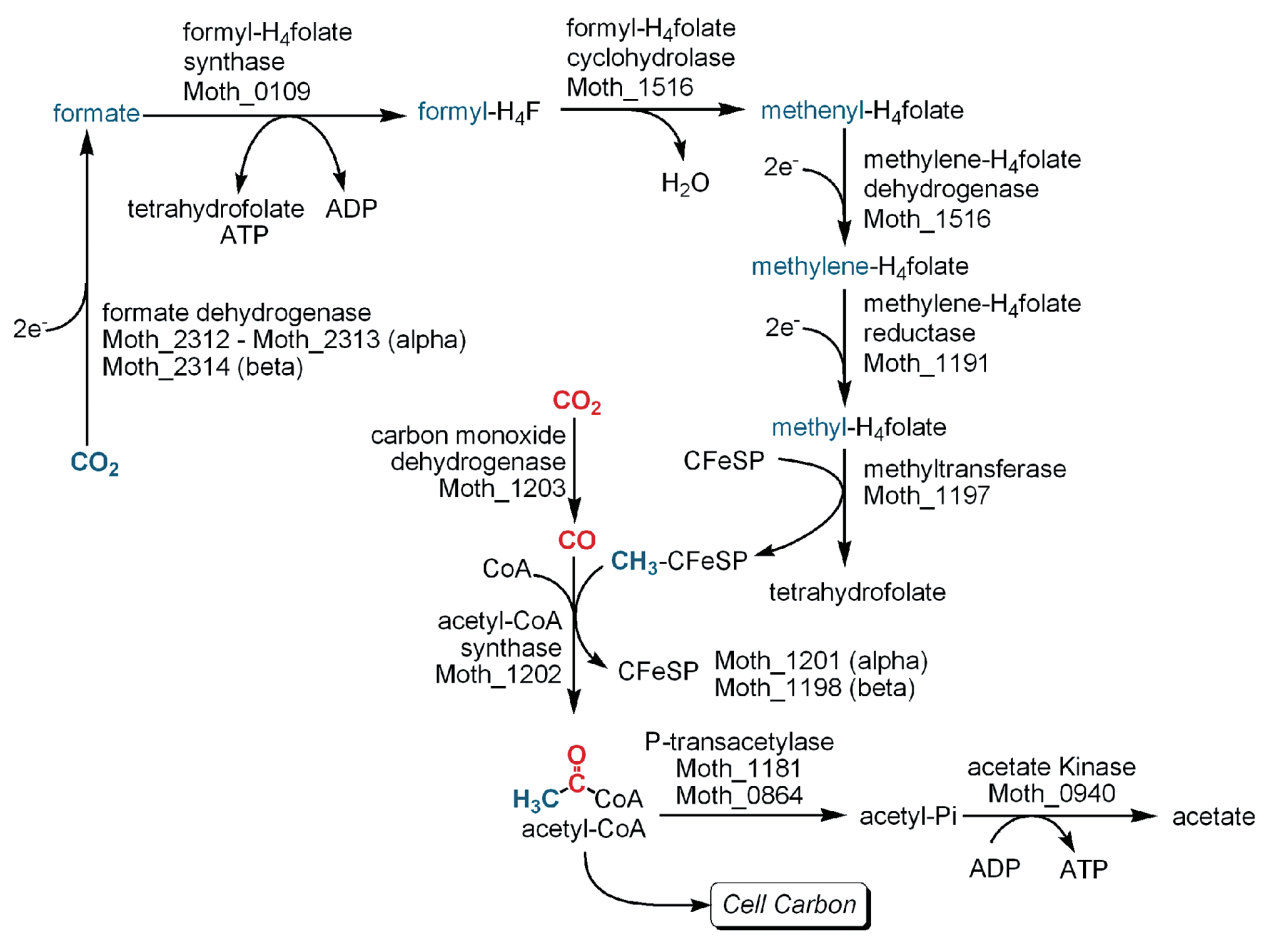

Fig. 2. The Wood-Ljungdahl pathway of $\mathrm{CO}_{2}$ fixation. Specific $M$. thermoacetica genes predicted or known to encode each step in the pathway are identified by locus tags, which can be used to find gene information at http://img.jgi.doe.gov. The C-1 groups are colour coded with the C-1 unit metabolized through the Eastern or methyl branch of the pathway shown in blue and the C-1 group in the Western or carbonyl branch shown in red.

cyclohydrolase and dehydrogenase are part of a bifunctional protein in M. thermoacetica, they are monofunctional proteins in other acetogens, e.g. Clostridium formicoaceticum and Acetobacterium woodii (Moore et al., 1974; Clark and Ljungdahl, 1982; Ragsdale and Ljungdahl, 1984).

The enzyme that catalyses the last step in the Eastern branch is encoded by the 5,10-methylene- $\mathrm{H}_{4}$ folate reductase gene (Moth_1191). In M. thermoacetica, this is an oxygen-sensitive enzyme containing an iron-sulfur cluster, zinc and FAD, which utilizes reduced ferredoxin as an electron donor (Clark and Ljungdahl, 1984; Park et al., 1991). Thauer and colleagues (1977) suggested that the 5,10-methylene- $\mathrm{H}_{4}$ folate reductase may link to an electron transport chain that begins with an electron donor (e.g. hydrogenase, $\mathrm{CODH}$ or $\mathrm{NADH}$ dehydrogenase)

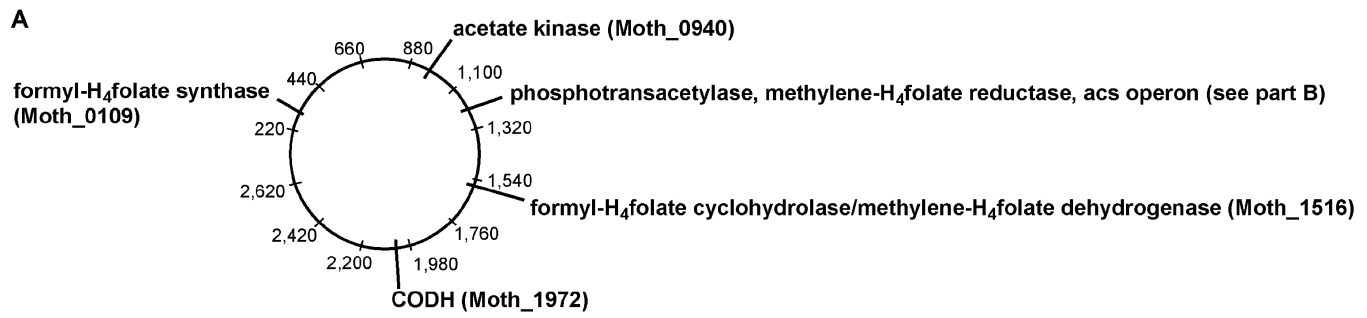

B

\begin{tabular}{|c|c|c|c|c|c|c|c|c|c|}
\hline $\operatorname{cooc}$ & $\operatorname{acs} A$ & $a c s B$ & $\operatorname{acs} C$ & orf7 & acsF & $a c s D$ & acs $E$ & $F$ & pduL \\
\hline $\begin{array}{r}\text { Moth_1204 } \\
\text { cooC }\end{array}$ & $\begin{array}{l}1203 \\
\mathrm{CODH}\end{array}$ & $\begin{array}{l}1202 \\
\text { ACS }\end{array}$ & $\begin{array}{l}1201 \\
\text { CFeSP }\end{array}$ & $\begin{array}{l}1200 \\
\text { ferredoxin }\end{array}$ & $\begin{array}{l}1199 \\
\text { acsF }\end{array}$ & $\begin{array}{l}1198 \\
\text { CFeSP }\end{array}$ & $\begin{array}{l}1197 \\
\text { methyl- } \\
\text { transferase }\end{array}$ & $\begin{array}{l}\overline{1191} \\
\text { methylene- } \\
\mathrm{H}_{4} \text { folate } \\
\text { reductase }\end{array}$ & $\begin{array}{l}1181 \\
\text { P-transacetylase }\end{array}$ \\
\hline
\end{tabular}

Fig. 3. Arrangement of Wood-Ljungdahl pathway genes in the acs gene cluster and in the chromosome.

A. Arrangement of Wood-Ljungdahl pathway genes on the circular chromosome of $M$. thermoacetica. The numbering shows kilobase pairs from the origin of replication.

B. The acs gene cluster that contains core Wood-Ljungdahl pathway genes discussed in the text. 
through membrane-bound electron carriers, finally to methylene- $\mathrm{H}_{4}$ folate. In this scenario, electron transport could result in the generation of a transmembrane proton potential coupled to ATP synthesis. In A. woodii, one of the steps involving methylene- $\mathrm{H}_{4}$ folate reductase, the methyltransferase or the CFeSP (see Fig. 2) was shown to generate a sodium motive force across the membrane (Heise et al., 1989). However, as the reductase appears to be located in the cytoplasm in $M$. thermoacetica (Clark and Ljungdahl, 1984) and in other organisms, it appeared that this is not the energy-conserving step in the WoodLjungdahl pathway (Muller, 2003). On the other hand, the location of the 5,10-methylene- $\mathrm{H}_{4}$ folate reductase gene very near genes encoding a hydrogenase (Moth_1193) and heterodisulfide reductase (Moth_1194-1196), which are directly downstream from the acs gene cluster (Moth_1197-1204), suggests a possible mechanism of energy conservation involving the reductase. Thus, perhaps methylene- $\mathrm{H}_{4}$ folate reductase links to the membrane-associated hydrogenase and/or heterodisulfide reductase to generate the proton motive force.

\section{Genes encoding the Western branch of the Wood-Ljungdahl pathway}

The core genes of the Western branch of the Wood-Ljungdahl pathway were first identified in $M$. thermoacetica by a reverse genetics approach to be located in the acs gene cluster (Fig. 3B), which contains genes encoding carbon monoxide dehydrogenase (CODH), acetyl-CoA synthase (ACS), methyltransferase (MeTr) and both subunits of the corrinoid iron-sulfur protein (CFeSP) (Roberts et al., 1989). The acs gene cluster also includes a gene encoding an iron-sulfur protein of unknown function (orf7), and two genes, cooC and $a c s F$, which encode proteins with sequences that are $44 \%$ and $27 \%$ identical to that of Rhodospirillum rubrum $\triangle O O C$, which is required for nickel insertion into carbon monoxide dehydrogenase (Jeon et al., 2001). Thus, the ubiquitous genes in the Eastern branch of the WoodLjungdahl pathway are scattered around the genome, while what can be considered to be the 'core set of WoodLjungdahl genes' in the Western part of the pathway are colocalized. The genome sequence reveals an additional carbon monoxide dehydrogenase (Moth_1972), which is similar to an uncharacterized carbon monoxide dehydrogenase from Clostridium cellulolyticum and to CODH IV from Carboxydothermus hydrogenoformans (Wu et al., 2005), and is unlinked to the acs gene cluster.

Phosphotransacetylase has been characterized from M. thermoacetica (Drake et al., 1981), but the gene sequence has not been reported. Moorella thermoacetica lacks any gene that is homologous to the phosphotransacetylase genes whose products are used for phospho- rylation of acetate from acetyl-CoA in related organisms, like Clostridium acetobutyricum (Boynton et al., 1996). However, Moth_1181 and Moth_0864 are homologous to the recently characterized pduL, which is used for 1,2propanediol degradation by Salmonella enterica (Liu et al., 2007). Therefore, Moth_1181 and Moth_0864 are likely to encode phosphotransacetylases in M. thermoacetica. The acetate kinase (Moth_0940) gene is distant from and, thus, is not linked to Moth_1181, Moth_0864 or the acs gene cluster; however, Moth_1181 is located only 16 genes downstream of the methyltransferase in the Wood-Ljungdahl pathway (or 10 genes further downstream from the gene encoding methylene$\mathrm{H}_{4}$ folate reductase).

\section{Comparison of Wood-Ljungdahl pathway gene clusters}

Acetyl-CoA synthase (COG1614, acsB) is found in five Clostridia, three Deltaproteobacteria and three Dehalococcoidetes species among the completely sequenced bacteria, and in the almost complete genome sequence of the uncultured bacterium Kuenenia stuttgartiensis (Strous et al., 2006), and seems to be a marker for the presence of the Wood-Ljungdahl pathway in bacteria. COG1614 is also found in archaea and corresponds to the $\sim 53 \mathrm{kDa}$ $\beta$-subunit that harbours the active site dinickel-iron-sulfur cluster of acetyl-CoA decarbonylase synthase in methanogens and archaeoglobus (Pfam 03598, cdhC) (MaupinFurlow and Ferry, 1996; Gencic and Grahame, 2003). From these genomes with acetyl-CoA synthase genes, only Dehalococcoides ethenogenes (Seshadri et al., 2005) and Dehalococcoides sp. BAV1 and CBDB1 do not have the complete Wood-Ljungdahl pathway. Though these genomes encode many enzymes that are part of the pathway, they lack homologues of known methylenetetrahydrofolate reductase, methyltransferase (acsE), $\mathrm{CO}$ dehydrogenase (acsA), phosphotransacetylase (pta or pduL) and acetate kinase sequences. We have been unable to locate any gene in the Dehalococcoides genome that is homologous to any of the CODH (acsA) genes from $M$. thermoacetica or $C$. hydrogenoformans. Given the small genome size and metabolic specialization of $D$. ethenogenes, one can speculate that the complete pathway was present in an ancestor, and has partly been lost as the organism's metabolism became limited to its current capabilities. Alkaliphilus metalliredigenes (Ye et al., 2004), C. hydrogenoformans (Wu et al., 2005), two Clostridium difficile strains, two Desulfitobacterium hafniense strains (Nonaka et al., 2006), Syntrophobacter fumaroxidans (Harmsen et al., 1998), Deltaproteobacterium MLMS-1, K. stuttgartiensis (Strous et al., 2006) and Candidatus Desulfococcus oleovorans $\mathrm{Hxd} 3$, formerly Deltaproteobacterium Hxd3 (So et al., 2003), appear to have complete Wood-Ljungdahl pathways, although 


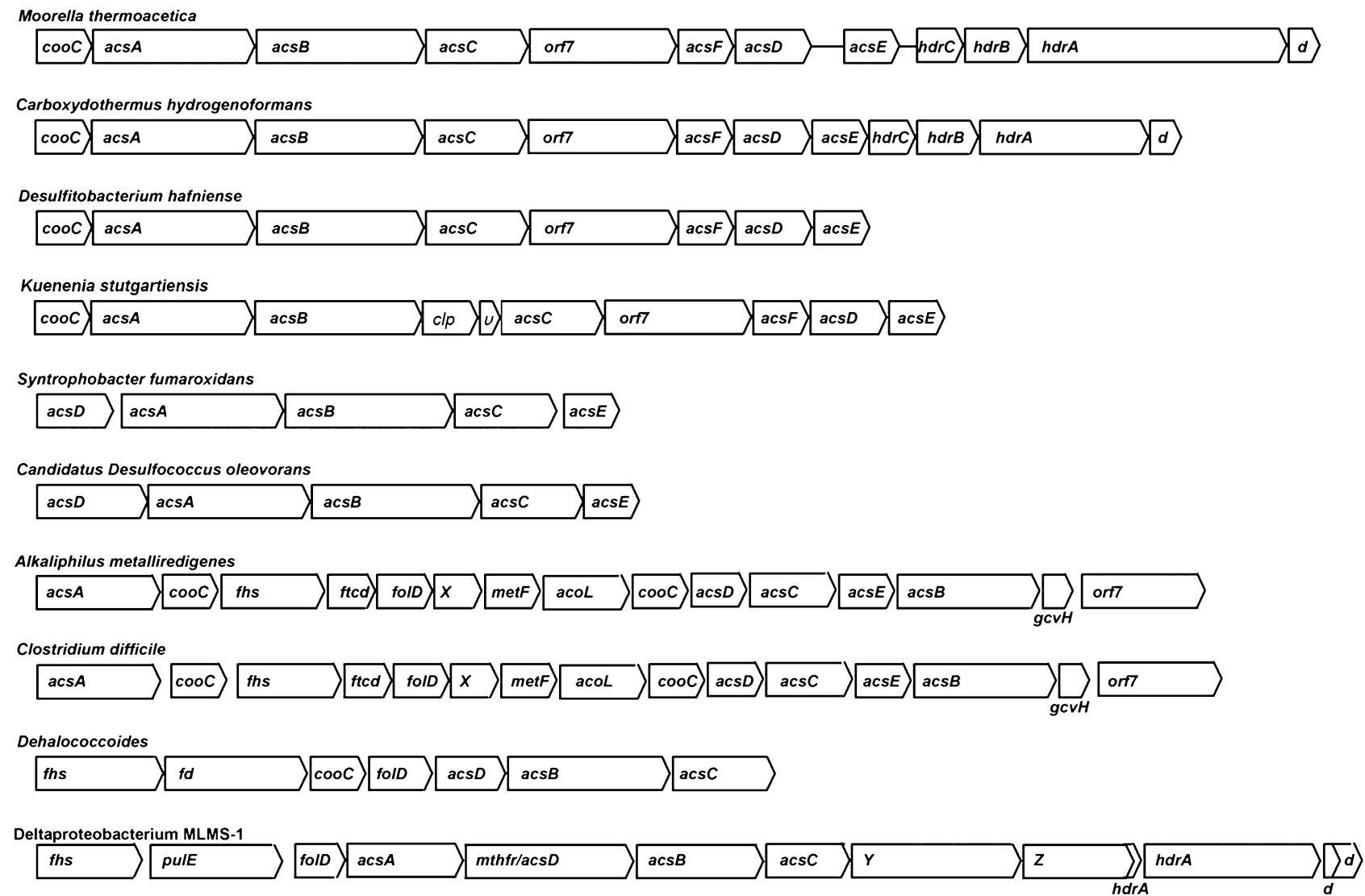

Fig. 4. Wood-Ljungdahl pathway gene clusters described in the text. Abbreviations are as follows: COoC: CODH chaperone; acsA: CODH; acsB: ACS; acsC: corrinoid iron-sulfur protein large subunit; orf7: unknown function; acsF: ACS chaperone similar to $\operatorname{cooC}$; acsD: corrinoid iron-sulfur protein small subunit; acsE: methyltransferase; $h d r C$ : heterodisulfide reductase subunit $C$; $h d r B$ : heterodisulfide reductase subunit $\mathrm{B}$; $h d r A$ : heterodislfide reductase subunit A; $d$ : similar to archaeal F420 reducing hydrogenase, $\delta$-subunit (COG1908); $c / p$ : similar to $c / p$ protease; $u$ : unknown function; fhs: formyl- $\mathrm{H}_{4}$ folate synthase; $f t c d$ : formimido- $\mathrm{H}_{4}$ folate cyclodeaminase; $X$ : zinc-finger protein of unknown function; metF: methylene- $\mathrm{H}_{4}$ folate reductase; acoL: dihydrolipoamide dehydrogenase; $g c v H$ : glycine cleavage system $\mathrm{H}$ protein; fd: ferredoxin; pulE: Type II secretory pathway, ATPase PuIE; folD: formyl- $\mathrm{H}_{4}$ folate cyclohydrolase/methylene- $\mathrm{H}_{4}$ folate dehydrogenase; $m$ thfr/acsD: methylene- $\mathrm{H}_{4}$ folate reductase/corrinoid iron-sulfur protein small subunit fusion; $Y$ : NADPH-dependent oxidoreductase (COG0493); Z: molybdopterin oxidoreductase (COG3383).

none of these organisms produces acetate as their main growth product.

As acetogenesis is a physiological trait that is not phylogenetically conserved (see Fig. 1), we reasoned that co-occurrence of acetyl-CoA synthase with a set of genes only in genomes of acetogenic bacteria could provide clues about which genes are required to confer the ability to grow as an acetogen. Thus, the M.thermoacetica genome was compared with those of all Firmicutes, Chlorflexi and Deltaproteobacteria available at IMG, using a BLAST analysis of each M. thermoacetica gene against these other genomes, to find $M$. thermoacetica genes with homologues in the other bacterial genomes that also have acetyl-CoA synthase, but without homologues in any of the sequences without acetyl-CoA synthase. The only genes that show this pattern of co-occurrence and co-omission are ACS and both subunits of the corrinoid iron-sulfur protein (CFeSP). The
CFeSP must have a highly conserved function as part of the Wood-Ljungdahl pathway, as homologues of the CFeSP genes are not found in any genome that does not also have acetyl-CoA synthase and other WoodLjungdahl pathway genes.

The Wood-Ljungdahl pathway gene clusters in these 12 bacteria can be divided into five groups within which the order of genes is absolutely conserved (Fig. 4). These groupings mostly follow the currently accepted taxonomy found at NCBI. The M. thermoacetica, $C$. hydrogenoformans, $D$. hafniense and $K$. stuttgartensis (group A) genes are arranged in the same way, and, like $M$. thermoacetica, C.hydrogenoformans has genes encoding heterodisulfide reductase directly following acsE. The K. stuttgartiensis gene cluster is identical in arrangement to the $D$. hafniense gene cluster, except for the insertion of a gene with sequence similar to clp protease sequences and one small gene of unknown function 


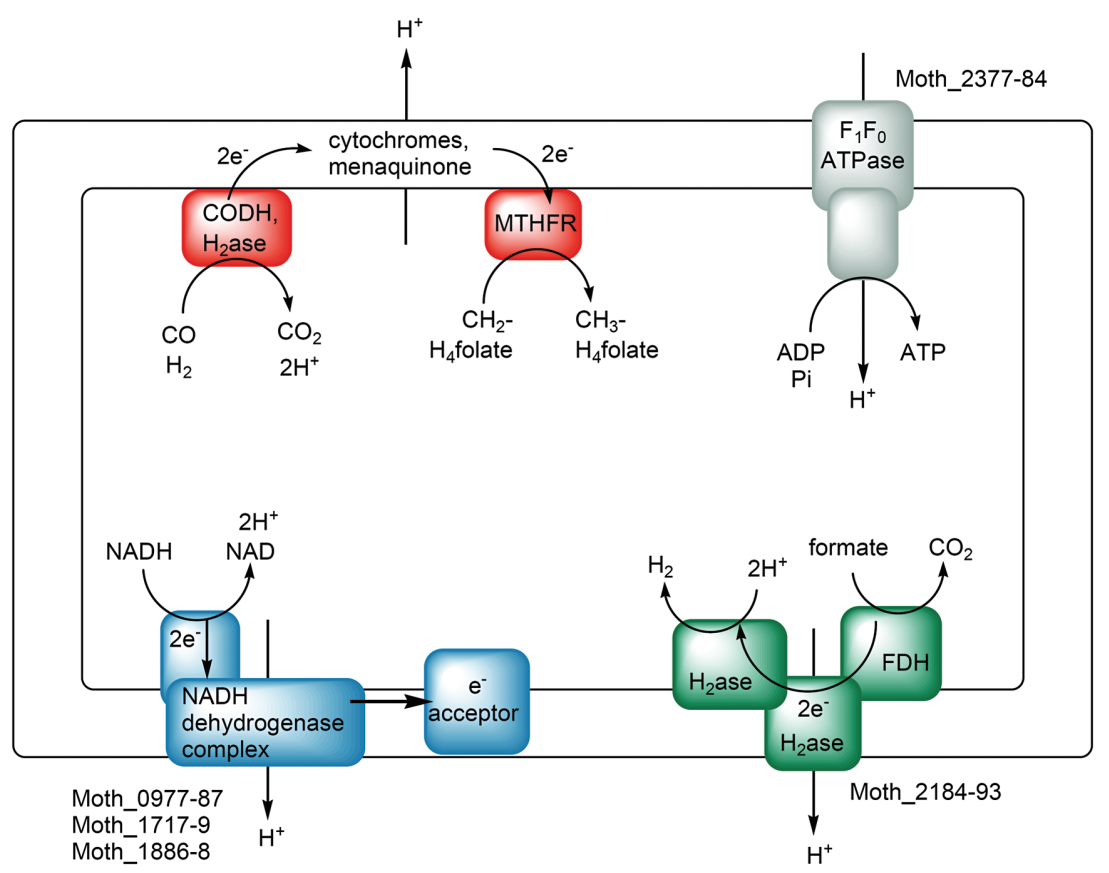

Fig. 5. Possible energy conserving pathways. Shown are pathways for growth by the Wood-Ljungdahl pathway (orange), using formate hydrogenlyase (green), or with alternate electron donors and acceptors, using NADH dehydrogenase I (blue). Under the right growth condition for each system, the system would generate a transmembrane proton gradient that could be used to drive ATP synthesis by the $F_{1} F_{0}$ ATPase (grey).

after acsB. The S. fumaroxidans and Candidatus $D$. oleovorans (group B) gene clusters are alike, and minimal, with only the acs $A B C D E$ genes. Candidatus $D$. oleovorans has four proteins in the same COG (3640) as the $M$. thermoacetica accessory proteins, and $S$. fumaroxidans has two proteins from this COG, but none of the genes encoding these putative accessory proteins are near the acs gene cluster in either species. $A$. metalliredigenes and $C$. difficile (group $\mathrm{C}$ ) have much larger Wood-Ljungdahl pathway gene clusters, which, besides the genes present in the $M$. thermoacetica acs gene cluster, include genes encoding formyltetrahydrofolate synthetase (fts), the bifunctional formyl-tetrahydrofolate cyclohydrolase/methylenetetrahydrofolate dehydrogenase $(f o l D)$, and methylenetetrahydrofolate reductase, which function in the Eastern branch of the pathway (Fig. 2). The three Dehalococcoides species (group D) have gene clusters that include $\operatorname{acs} B C D$, fts and folD; however, they surprisingly lack acsA. The Deltaproteobacterium MLMS-1 gene cluster (group E) is similar to the Dehalococcoides WoodLjungdahl gene clusters, but includes acs $A$, genes which belong in COG0493 and COG3383 (see the anaerobic respiration and electron acceptors discussions), one heterodisulfide reductase subunit $A$ gene, and two genes encoding homologues of the archaeal hydrogenase $\delta$-subunit that is found in the HDR gene clusters in $M$. thermoacetica. Based on this analysis, it appears that the core genes of the Wood-Ljungdahl pathway are located in the acs gene cluster, which includes acsAacsE, and acquisition of this gene cluster might be sufficient for gaining the ability to grow as an acetogen.
Genes involved in anaerobic respiration

In the Wood-Ljungdahl pathway, one ATP is consumed in the formation of formyl-tetrahydrofolate from tetrahydrofolate and formate in the formyl-tetrahydrofolate synthase reaction (Sun et al., 1969), and one is generated by phosphoryl transfer to ADP in the acetate kinase reaction (Fig. 2) (Schaupp and Ljungdahl, 1974). Therefore, there is no net gain of ATP by substrate level phosphorylation during autotrophic growth. Thus, it is clear that ATP is generated by anaerobic respiration. During growth using the Wood-Ljungdahl pathway, energy should be conserved by transfer of electrons along a membrane-bound electron transfer chain, coincident with generation of a transmembrane proton gradient (Fig. 5). Moorella thermoacetica has an $\mathrm{F}_{1} \mathrm{~F}_{0}$ ATP synthase, which could use this proton gradient to drive ATP synthesis (Das and Ljungdahl, 1997). The genes encoding the eight subunits of the ATP synthase are Moth_2377-84. Moorella thermoacetica has integral membrane-bound electron carriers including $b$ cytochromes (see Table 2) and a menaquinone (Gottwald et al., 1975; Hugenholtz et al., 1987; Das et al., 1989) that could be part of this system. There is evidence in the $M$. thermoacetica genome for genes that encode systems that could be associated with energy generation by transmembrane proton gradient formation (Table S2), including NADH dehydrogenase, hydrogenase or formate hydrogen lyase and heterodisulfide reductase.

There is considerable homology of both subunit compositions and sequences among NADH dehydrogenases and some energy conserving $\mathrm{NiFe}$ hydrogenases 
Table 2. Cytochromes present in the $M$. thermoacetica genome.

\begin{tabular}{lll}
\hline Locus tag & Annotation & COG \\
\hline Moth_0452 & Formate dehydrogenase, $\gamma$-subunit (cytochrome $b)^{\mathrm{a}}$ & COG2864 \\
Moth_1605 & Cytochrome $c$ family protein & No cog \\
Moth_2095 & Cytochrome $b d$ ubiquinol oxidase, subunit I & COG1271 \\
Moth_2096 & Cytochrome $d$ ubiquinol oxidase, subunit II & COG1294 \\
\hline
\end{tabular}

a. This formate dehydrogenase is different than the selenocystine-containing formate dehydrogenase identified experimentally by Li, Ljungdahl and Gollin in GenBank (gi 1658401)

(Deppenmeier, 2004; Hedderich, 2004). Examples of the former are mitochondrial complex I and Escherichia coli $\mathrm{NADH}$ dehydrogenase I. The latter include E. coli hydrogenases 3 and 4 , which are parts of formate hydrogen lyase complexes (Andrews et al., 1997), the CO-inducible hydrogenase from Rhodospirillum rubrum (Fox et al., 1996), a CO dehydrogenase-associated hydrogenase from C. hydrogenoformans (Soboh et al., 2002), and the Ech hydrogenase of Methanosarcina barkeri (Meuer et al., 1999). Two sets of M. thermoacetica genes, Moth_0977-87 and Moth_2184-92, encode proteins homologous to these complexes. A BLAST search of C. hydrogenoformans, E. coli, M. barkeri and R. rubrum genomes with genes from Moth_0977-87 (Table 3) shows that these genes are most closely related to NADH dehydrogenase I in bacteria, and to the $F_{420}$-dependent hydrogenase of $M$. barkeri. In some bacteria, as shown in Table 3 for $R$. rubrum and E. coli, the NADH dehydrogenase operon contains genes encoding subunits $E, F$ and $\mathrm{G}$ of the NADH dehydrogenase complex. In $M$. thermoacetica, homologues to these subunits are encoded separately, on two different gene clusters, Moth 1717-9 and Moth_1886-8. Moth_ 1717 and Moth_ 1888 align only with the first 240 and 280 amino acids of NuoG sequences from E. coli and Thermus thermophilus. In T. thermophilus, this $\mathrm{N}$-terminal portion of the protein has the residues that ligate the three iron-sulfur clusters that are involved in electron transfer through the NADH dehydrogenase complex (Sazanov and Hinchliffe, 2006).

Proteins encoded by Moth_2184-92 (Table 4) are most closely related to $E$. coli hydrogenases 4 and 3 among experimentally characterized proteins. In C. hydrogeno-

Table 3. Comparison of Moth_0977-87 with genes encoding C. hydrogenoformans, $R$. rubrum and E. coli NADH dehydrogenase I and M. barkeri F-420-dependent hydrogenase.

\begin{tabular}{|c|c|c|c|c|c|}
\hline M. thermoacetica & C. hydrogenoformans & R. rubrum & E. coli & M. barkeri & COG \\
\hline Moth_0977 & CHY_1415 & Rru_A1555 & b2288 ${ }^{a}$ & Mbar_A3412 & 0838 \\
\hline Moth_0978 & $\mathrm{CHY}-1416$ & Rru_A1556 & b2287 & Mbar_A3411 & 0388 \\
\hline Moth_0979 & $\mathrm{CHY}^{-} 1417$ & Rru_A1557 & $\mathrm{NH}$ & Mbar_A3410 & 0852 \\
\hline Moth_0980 & $\mathrm{CHY}_{-} 1418$ & Rru_A1558 & b2286 & Mbar_A3409 & 0649 \\
\hline$N G$ & $N G$ & Rru_A1559-61 ${ }^{a}$ & $\mathrm{~b} 2285-3^{\mathrm{a}}$ & $N G$ & $1905,1894,1034$ \\
\hline Moth 0981 & CHY 1419 & Rru A1562 & b2282 & Mbar A3408 & 1005 \\
\hline Moth_0982 & $\mathrm{CHY}_{-1420}$ & Rru_A1563 & b2281 & Mbar_A3407 & 1143 \\
\hline Moth_0983 & CHY_1421 & Rru_A1564 & b2280a & Mbar_A3406 & 0839 \\
\hline$N G$ & $\mathrm{NG}$ & $N G$ & $N G$ & Mbar_A3405 & 0713 \\
\hline Moth_0984 & CHY_1422 & Rru_A1565 & b2279 & Mbar_A3404 & 1009 \\
\hline Moth_0985 & CHY_1423 & Rru_A1566 & b2278 & Mbar_A3403 & 1009 \\
\hline Moth 0986 & $\mathrm{CHY}^{-} 1424$ & Rru A1567 & b2277 & Mbar A3402 & 1008 \\
\hline \multirow[t]{2}{*}{ Moth_0987 } & $\mathrm{CHY}_{-}^{-1425}$ & Rru_A1568 & b2276 & Mbar_A3401 & 1007 \\
\hline & Subunit designation & & & & \\
\hline Moth_0977 & $A$ & & & & \\
\hline Moth_0978 & B & & & & \\
\hline Moth_0979 & $\mathrm{C}$ & & & & \\
\hline Moth_0980 & D & & & & \\
\hline$N G$ & $\mathrm{EFG}$ & & & & \\
\hline Moth_0981 & $\mathrm{H}$ & & & & \\
\hline Moth_0982 & I & & & & \\
\hline Moth_0983 & $\mathrm{J}$ & & & & \\
\hline \multicolumn{6}{|l|}{ NG } \\
\hline Moth_0984 & $\mathrm{K}$ & & & & \\
\hline Moth_0985 & $\mathrm{L}$ & & & & \\
\hline Moth_0986 & $\mathrm{M}$ & & & & \\
\hline Moth_0987 & $\mathrm{N}$ & & & & \\
\hline
\end{tabular}

a. These genes do not have reciprocal best hits with genes in the M. thermoacetica gene cluster (Moth_0977 to Moth_0987).

The BLAST cut-off is $E$-value $<1 E^{-2}$.

$\mathrm{NG}$, no homologous gene is present in this gene cluster; $\mathrm{NH}$, no gene in this organism is a BLAST hit with the corresponding $M$. thermoacetica gene. 
Table 4. Comparison of Moth_2184-92 with hydrogenases from C. hydrogenoformans and E. coli.

\begin{tabular}{|c|c|c|c|c|c|c|}
\hline M. thermoacetica & C. hydrogenoformans & E. coli hydrogenase 3 & E. coli hydrogenase 4 & & & \\
\hline Moth_2184 & CHY_1830 & $\mathrm{COOL}$ & b2719 & hycG & b2489a & hyfl \\
\hline Moth 2185 & $\mathrm{CHY}^{-} 1829$ & $\operatorname{coo} X$ & b2720a & hycF & b2488 & hyfH \\
\hline Moth_2186 & $\mathrm{CHY}^{-} 1827$ & $\mathrm{COOH}$ & b2721 & hycE & b2487a & hyfG \\
\hline Moth_2187 & CHY_1832a & cooM & $\mathrm{NH}$ & & b2486 & hyfD \\
\hline Moth_2188 & $\mathrm{CHY}_{-}^{-} 1832^{\mathrm{a}}$ & cooM & b2723 ${ }^{a}$ & hycC & b2485 & hyfF \\
\hline Moth_2189 & $\mathrm{NH}^{-}$ & & $\mathrm{NH}$ & & b2484 & hyfE \\
\hline Moth_2190 & CHY_1831 & cooK & b2722 ${ }^{a}$ & hycD & b2483 & hyfC \\
\hline Moth_2191 & CHY_1832 & cooM & b2723 ${ }^{a}$ & hycC & b2482 & hyfB \\
\hline \multirow[t]{2}{*}{ Moth_2192 } & $\mathrm{CHY}_{-} 1825^{\mathrm{a}}$ & $\mathrm{COOF}$ & b2724 & hycB & b2481 & hyfA \\
\hline & COG & & & & & \\
\hline Moth_2184 & 3260 & & & & & \\
\hline Moth_2185 & 1143 & & & & & \\
\hline Moth_2186 & 3261 & & & & & \\
\hline Moth_2187 & 1009 & & & & & \\
\hline Moth_2188 & 0651 & & & & & \\
\hline Moth_2189 & 4237 & & & & & \\
\hline Moth_2190 & 0650 & & & & & \\
\hline Moth_2191 & 0651 & & & & & \\
\hline Moth_2192 & 1142 & & & & & \\
\hline
\end{tabular}

a. These genes do not have reciprocal best hits with genes in the M. thermoacetica gene cluster (Moth_2184 to Moth_2192).

$\mathrm{NH}$, no BLAST hit with $E$-value $<1 E^{-2}$ in this gene cluster.

formans, Moth_2184-88 and Moth_2190-92 are most closely related to $\mathrm{CO}$-associated hydrogenase, although there is lower sequence homology between these $M$. thermoacetica genes and CO-associated hydrogenase than between Moth_2184-92 and E. coli hydrogenases 3 and 4. Moth_2184-90 are more similar to subunits of hydrogenase 4 than subunits of hydrogenase 3, and Moth_2187-89 encode homologues of E. coli hydrogenase four genes hyfDEF, which do not have homologues in hydrogenase 3 . Hydrogenase 3 does not generate a proton gradient, and probably is used by E. coli to metabolize formate produced during fermentative growth. From their analysis of the hyf gene cluster, Andrews and colleagues (1997) concluded that hydrogenase 4 is likely to have proton-translocating ability (although this has not been verified experimentally), because, like the NADH dehydrogenase I complex and the $R$. rubrum CO-inducible hydrogenase, and unlike hydrogenase 3 from $E$. coli, hyfBEF are homologous to ND2, ND4 and ND5 components of the quinone-reducing and proton translocating machinery in NADH dehydrogenase I. Moorella thermoacetica genes Moth_2176-83, which are immediately downstream from this second gene cluster, are homologues of the hypA- $F$, hycl and $h y c H$ genes of $E$. coli, which make up an operon that is required for maturation of the $\mathrm{Ni}-\mathrm{Fe}$ hydrogenase 3 (Lutz et al., 1991; Blokesch et al., 2004). Immediately upstream of the hydrogenase gene cluster is a gene encoding a selenocysteine-containing formate dehydrogenase (Moth_2193) that is separate from the formate dehydrogenase that feeds formate into the Wood-Ljungdahl pathway. It is likely that Moth_2184-93 encodes a formate hydrogenlyase system, which by homology to hydrogenase 4 , could generate a proton gradient in the presence of formate.

In methanogenic archaea, hydrogenases distinct from the Ech hydrogenase discussed above are also involved in energy generation as parts of membrane-bound electron transport systems, along with heterodisulfide reductase. In these systems, electrons are transferred from hydrogen to the disulfide formed between coenzyme $M$ and coenzyme B during the last step in methanogenesis. Both two-subunit haem $b$-containing and three-subunit (non-haem) heterodisulfide reductases have been characterized (Setzke et al., 1994; Deppenmeier, 2004). Although it is not an archaeon, $M$. thermoacetica has three heterodisulfide reductase gene clusters that are homologous to the three-subunit heterodisulfide reductase from Methanothermobacter marburgensis (Table 5), one of which (Moth_1196) is directly after the CODH/ACS gene cluster. Moth_0441 (a heterodisulfide reductase A subunit) includes about 200 amino acids (from 400 to 600) that do not align with HdrA domains from Methanosarcina or most bacterial hits. These amino acids align with lower $E$-values with sequences from Syntrophobacter fumaroxidans, Methanosarcina mazei, an uncultured archaeon, Desulfotomaculum reducens, two Geobacter species and Candidatus D. oleovorans. Moth_1194 aligns with HdrA, except between amino acids 150 and 550. This region aligns with COG0493, which is made of the NADPH-dependent glutamate synthase $\beta$-chain, and related oxidoreductases. Moth_0811 and Moth_0812 make up one selenocysteinecontaining gene, which aligns with other HdrA sequences along its full length. 
Table 5. Heterodisulfide reductase gene clusters in the M. thermoacetica genome.

\begin{tabular}{llr}
\hline Locus tag & Annotation & COG \\
\hline Moth_0439 & Heterodisulfide reductase subunit C-like (sequence is shorter) & COG1150 \\
Moth_0440 & Heterodisulfide reductase subunit B & COG2048 \\
Moth_0441 & Heterodisulfide reductase subunit A & COG1148 \\
Moth_0442 & Similar to archaeal F420 reducing hydrogenase, $\delta$-subunit & COG1908 \\
Moth_0809 & Heterodisulfide reductase subunit C & COG1150 \\
Moth_0810 & Heterodisulfide reductase subunit B & COG2048 \\
Moth_0811 & Heterodisulfide reductase selenocysteine containing subunit A & COG1148 \\
Moth_0812 & Heterodisulfide reductase selenocysteine containing subunit A & COG1148 \\
Moth_0813a & Selenocysteine containing methyl viologen-reducing hydrogenase, $\delta$-subnit & COG1908 \\
Moth_1193 & Similar to archaeal F420 reducing hydrogenase, $\delta$-subunit & COG1908 \\
Moth_1194 & NADPH-dependent glutamate synthase $\beta$-chain and related & COG1148 \\
& oxidoreductases (COG0493), Heterodisulfide reductase subunit A (COG1148) & COG0493 \\
Moth_1195 & Heterodisulfide reductase subunit B & COG2048 \\
Moth_1196 & Heterodisulfide reductase subunit C & COG1150 \\
Moth_1452 & Unknown function & COG0247 \\
Moth_1453 & Heterodisulfide reductase A & COG1148 \\
Moth_1454 & FAD-dependent oxidoreductase/NAD(P)H-dependent reductase & COG1251 \\
\hline
\end{tabular}

a. These M. thermoacetica genes are annotated by similarity to COGs 1908 and 1251, not by alignment with specific protein sequences.

\section{Genes involved in autotrophic growth}

One-carbon compounds that $M$. thermoacetica can use for growth include $\mathrm{H}_{2} / \mathrm{CO}_{2}$, $\mathrm{CO}$, formate, methanol and methyl groups from many methoxylated aromatic compounds. The enzymes that catalyse transfer of the methyl group of methoxylated aromatic compounds to tetrahydrofolate are encoded by $m t v A B C$ (Moth_0385-7 and Moth_1316-8) and have been purified and identified biochemically by enzymatic function and protein sequence analysis (Naidu and Ragsdale, 2001). This pathway is shown in Fig. 6, along with that of a methanol methyltransferase system (MtaABC, encoded by (Moth_1208-9 and Moth_2346) was recently characterized from M. thermoacetica (Das et al. 2007). Moorella thermoacetica has two nearly identical $m t v A$ genes, each of which is next to a gene that we assign as $m t v B$, and a predicted cobalamin-binding $m t v C$ gene. The putative $m t v B$ genes are $80 \%$ identical to each other, and the $m t v C$ genes differ by one amino acid. Both $m t v A$ and $m t v C$ genes are similar to cobalamin-dependent methionine synthase (5-methyltetrahydrofolate:homocysteine S-methyltransferase, encoded by $\mathrm{metH}$ in $\mathrm{E}$. coli).

The two $m t v B$ genes are most similar to uroporphyrinogen decarboxylase sequences, among experimentally characterized proteins, although the function of MtvB is clearly associated with methyl transfer. In addition to these $m t v$ genes, M. thermoacetica encodes several homologues of MtvA, MtvB and MtvC (Table 6). It is possible that some of these homologues are used for growth on methyl donors other than vanillate and methanol. Many homologues of the $M$. thermoacetica MtvA and $C$ proteins are also found in $D$. hafniense, which can also demethylate methoxylated aromatic compounds (Neumann et al., 2004). These are arranged in clusters with $A$ and $C$ genes and sequences aligning either with $M$. thermoacetica MtvB or sequences of similar function from Acetobacterium dehalogenans. One of the $M$. thermoacetica MtvB homologues (Moth_1314) is fused to a domain that has not been functionally identified, and does not align with any $\mathrm{COG}$ identified at NCBI. Sequences that align with this whole fusion are found in D. hafniense, Archaeoglobus fulgidus and $A$. metalliredigenes.

\section{Genes involved in heterotrophic growth}

Moorella thermoacetica can grow heterotrophically on fructose, glucose, xylose, ethanol, $n$-propanol, $n$-butanol (Beaty and Ljungdahl, 1991), oxalate and glyoxylate (Daniel and Drake, 1993), glycolate (Seifritz et al., 1999), pyruvate (Barker and Kamen, 1945) and lactate (Gößner et al., 1999). Moorella thermoacetica encodes a complete Embden-Meyerhof-Parnas pathway and all enzymes that are part of the oxidative branch of the pentose phosphate pathway (Fig. S2). Glucose and xylose are converted stoichiometrically to acetate by $M$. thermoacetica (Fontaine et al., 1942; Barker and Kamen, 1945). It seems likely that fructose is metabolized by the same pathway as glucose (Fig. S3), as growth yields of the two substrates are very similar (Andreesen et al., 1973).

Ethanol, propanol and butanol are oxidized to acetate, propionate and butyrate by $M$. thermoacetica (Beaty and Ljungdahl, 1991). Eight genes from four COGs containing alcohol dehydrogenases are present in the genome (Table S3). Proteins encoded by three genes from COG2414, tungsten-containing aldehyde:ferredoxin oxidoreductases, might catalyse the second step in growth on these alcohols.

The pathways for growth of $M$. thermoacetica on the two-carbon substrates oxalate, glyoxylate and glycolate 


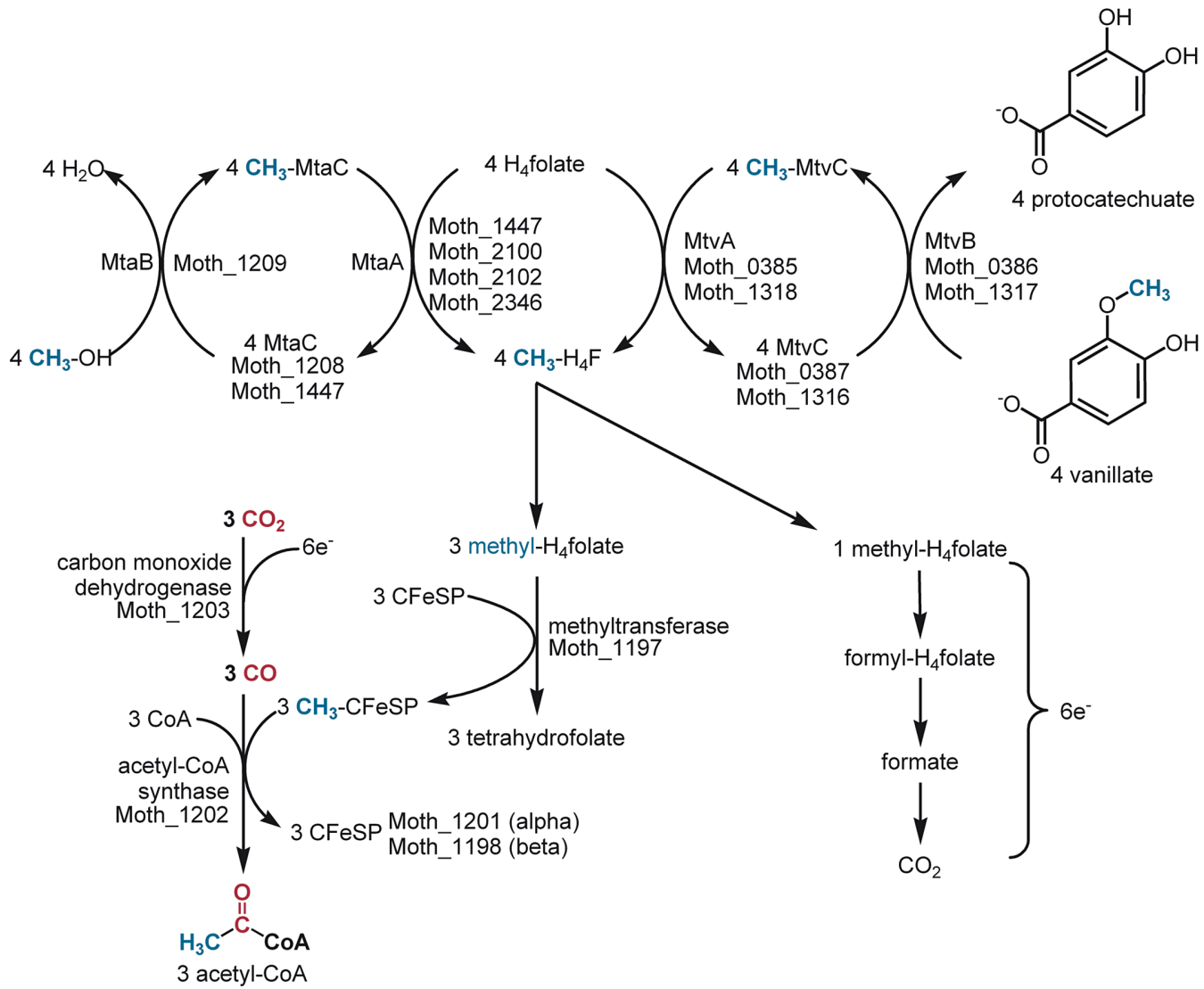

Fig. 6. Methyl groups from methanol and vanillate linked to the Wood-Ljungdahl pathway. Demethylation of vanillate or methanol provides preformed methyl groups to the Wood-Ljungdahl pathway. Three moles of acetyl-CoA are formed from 4 mol of methanol or vanillate, because oxidation of one methyl group provides six electrons that reduce $3 \mathrm{~mol}$ of $\mathrm{CO}_{2}$ to $3 \mathrm{~mol}$ of $\mathrm{CO}$, which can be used in the synthesis of three acetyl-CoA molecules. The $\mathrm{C}-1$ units are labelled as in Fig. 2.

Table 6. MtvA, MtvB and MtvC homologues in the M. thermoacetica genome.

\begin{tabular}{lll}
\hline Locus tag & Annotation & COG \\
\hline Moth_0385 & MtvA & COG1410 \\
Moth_0386 & MtvB & COG0407 \\
Moth_0387 & MtvC & COG5012 \\
Moth_1197 & AcsE (methyl-THF corrinoid FeS protein methyltransferase) & COG1410 \\
Moth_1206 & MtvC homologue & COG5012 \\
Moth_1207 & MtvA homologue & COG1410 \\
Moth_1208 & MtaC & COG5012 \\
Moth_1209 & MtaB & No COG \\
Moth_1213 & MtvC homologue & COG1410 \\
Moth_1311 & MtvC homologue & COG5012 \\
Moth_1314 & MtvB plus an N-terminal domain & COG0407 \\
Moth_1316 & MtvC & COG5012 \\
Moth_1317 & MtvB & COG0407 \\
Moth_1318 & MtvA & COG1410 \\
Moth_1447 & MtaA/MtaC & COG0407, COG 5012 \\
Moth_2100 & COG0407 \\
Moth_2102 & MtaA & COG0407 \\
Moth_2114 & MtvC homologue/histidine kinase fusion protein \\
Moth_2115 & CoG5012, COG2972 \\
Moth_2116 & COG1410 \\
Moth_2346 & MtrC homologue & COG5012 \\
\hline
\end{tabular}

(C) 2008 The Authors

Journal compilation @ 2008 Society for Applied Microbiology and Blackwell Publishing Ltd, Environmental Microbiology, 10, 2550-2573 
are not known. The stoichiometries of acetate production suggest that they are oxidized by two, four and six electrons respectively (Seifritz et al., 1999). Given differences in growth on these three substrates, it seems likely that $M$. thermoacetica uses different pathways for their oxidation. Only partial pathways known to be involved in glycolate metabolism in other organisms are present in M. thermoacetica. In E. coli, the glycolate metabolism genes are located in an operon, which includes glcA (encodes a glycolate permease), glcB (encodes malate synthase), glcG (function is unknown), glcF, $E$ and $D$ (encode the three subunits of glycolate oxidase) and glcC (encodes a transcriptional activator) (Pellicer et al., 1996), and the first enzymatic step is oxidation of glycolate to glyoxylate via an FMN-dependent oxidase (GICDEF). The M. thermoacetica genes are arranged in two clusters, one containing glcDEF homologues (Moth_0037-39), and the other containing homologues to glcACF, an unknown protein, another $g / c F$, and a sequence that aligns with $g l c D$ and $E$ (Moth_2303-8). The glycolate permease gene $(g / c A)$ in E. coli and the proposed $M$. thermoacetica $g / c A$ are very similar to L-lactate permeases (Núñez et al., 2001). No homologue of malate synthase was found in $M$. thermoacetica, but M. thermoacetica does have a gene, Moth_1954, with $51 \%$ sequence identity to a possible glyoxylate reductase that has been purified from Thermococcus litoralis (Ohshima et al., 2001). This enzyme catalyses formation of malate from glyoxylate and acetyl-CoA and is homologous to D-lactate dehydrogenase.

Moorella thermoacetica is able to grow on lactate and pyruvate. Lactate is probably converted to pyruvate by Moth_1826, which is similar to both Clostridium acetobutylicum and Thermotoga maritima L-lactate dehydrogenases. Pyruvate is metabolized using pyruvate:ferredoxin oxidoreductase (PFOR), which catalyses the oxidative cleavage of pyruvate and attachment of the two carbon fragment to $\mathrm{CoA}$, forming acetyl-CoA, $\mathrm{CO}_{2}$ and reduced ferredoxin (Fig. S4). PFOR is also essential in sugar metabolism, as it couples the EmbdenMeyerhoff-Parnas pathway to the Wood-Ljungdahl pathway. In sugar metabolism, four additional electrons are available from the glyceraldehyde-phosphate dehydrogenase reaction, so $1 \mathrm{~mol}$ of glucose (i.e. $2 \mathrm{~mol}$ of pyruvate) is required to supply the eight electrons for reducing $2 \mathrm{~mol}$ of $\mathrm{CO}_{2}$ to acetate. The PFOR that has been purified from $M$. thermoacetica is a homodimer, with a subunit mass of $120 \mathrm{kDa}$ (Furdui and Ragsdale, 2002). The gene encoding this enzyme, Moth_0064, is a fusion of three COGs, COG0674, COG1014, COG1013, which are annotated as $\alpha-, \gamma$ - and $\beta$-subunits. Five other sets of genes belonging to the same COGs as PFOR (Table S4) could encode authentic PFORs, but they could also encode other proteins in the oxoglutamate oxidoreduc- tase family, like 2-ketoisovalerate oxidoreductase, indolepyruvate oxidoreductase and 2-ketoglutarate oxidoreductase. Many of the residues that are known to be important in the well-characterized PFOR from Desulfovibrio africanus are conserved in the PFOR-like gene clusters of $M$. thermoacetica. These include residues that bind iron-sulfur clusters, thiamine pyrophosphte and pyruvate. Conservation of these residues suggests that these $M$. thermoacetica gene clusters likely encode enzymes that perform similar functions to PFOR. Variation in the residue that forms a hydrophobic interaction with the methyl group of pyruvate in the $D$. africanus enzyme could be due to different substrate specificity of the protein products of these different gene clusters. For example, the replacement of this residue with a glycine residue could accommodate a substrate larger than pyruvate.

Genes involved in utilization of electron acceptors other than $\mathrm{CO}_{2}$

Moorella thermoacetica can use electron acceptors other than $\mathrm{CO}_{2}$ during heterotrophic growth. When nitrate and $\mathrm{CO}_{2}$ are both supplied, nitrate is used preferentially (Seifritz et al., 1993). In medium containing a carbon source for heterotrophic growth, addition of nitrate stimulates growth, and reducing equivalents from $\mathrm{H}_{2}$ and onecarbon substrates are used to make ammonium, while acetate production is decreased. Work by Fröstl et al., 1996; Arendsen et al., 1999 suggests that carbon incorporation through the Wood-Ljungdahl pathway is repressed by nitrate. Nitrite (Seifritz et al., 2003), dimethylsulfoxide and thiosulfate (Beaty and Ljungdahl, 1991) are also electron sinks for $M$. thermoacetica. Some of these electron acceptors could be reduced by oxidoreductases similar to DMSO and TMAO reductases found in E. coli and many other organisms. These proteins use molybdopterin cofactors, are often membrane associated, and in some cases are transported to the periplasm by twin-arginine transport (TAT) systems.

Moorella thermoacetica genes similar to the E. coli DMSO and TMAO reductases have been identified. The E. coli DMSO reductase has three subunits. DmsA is the molybdopterin-containing catalytic subunit (COG0243), DmsB is an iron-sulfur electron transfer subunit (COG0437), and DmsC is a membrane anchor subunit (COG3302). TMAO reductase has a cytochrome subunit instead of DmsC and B-like subunits. Moorella thermoacetica has eight genes belonging to COGs 0243 and 3383, which are made up of molybdopterin-containing proteins, shown in Table 7. Five of these genes are adjacent to COG0437 proteins. One homologue of the E. coli DmsC subunit is also present in M. thermoacetica. No oxidoreductase subunit homologous to the pentaheme 
Table 7. Gene clusters containing predicted molybdopterin subunits in COGs 0243 and 3383.

\begin{tabular}{lll}
\hline Locus tag & Annotation & COG \\
\hline Moth_0450 & Molybdopterin subunit, TAT sequence & COG0243 \\
Moth_0451 & Iron sulfur cluster containing subunit & COG0437 \\
Moth_0452 & Cytochrome b556 subunit of formate dehydrogenase & COG2864 \\
Moth_1379 & TorD & COG3381 \\
Moth_1381 & Iron sulfur cluster containing subunit & COG0437 \\
Moth_1382 & Molybdopterin containing subunit & COG0243 \\
Moth_1384 & DmsC type membrane anchor subunit & COG3302 \\
Moth_1385 & Iron sulfur cluster containing subunit & COG0437 \\
Moth_1386 & Molybdopterin subunit, TAT sequence & COG0243 \\
Moth_1388 & Iron sulfur cluster containing subunit & COG0437 \\
Moth_1389 & Molybdopterin subunit, TAT sequence & COG0243 \\
Moth_1390 & TorD & COG3381 \\
Moth_1906 & Polysulfide reductase, integral membrane protein & COG5557 \\
Moth_1907 & Iron sulfur cluster containing subunit & COG0437 \\
Moth_1908 & Molybdopterin subunit, TAT sequence & COG0243 \\
Moth_1909 & Molybdopterin containing subunit & COG3383 \\
Moth_2193 & Se-containing formate hydrogen lyase subunit & COG3383 \\
Moth_2312-13 & Se-containing formate dehydrogenase subunit & COG3383 \\
Moth_2314 & Predicted NADPH-dependent oxidoreductase & COG0493 \\
\hline
\end{tabular}

cytochrome $c$ family TorC subunit of the TMAO reductase in E. coli (gi 2506330, COG3005; Gon et al., 2001) was found in M. thermoacetica. This subunit connects TMAO reductase in $E$. coli with respiration via the quinone pool. Thus, in M. thermoacetica, it is likely that one of the electron transfer proteins discussed above in the Anaerobic Respiration section couples TMAO and DMSO-derived electrons to the quinone pool.

Analysis of the $\mathrm{N}$-terminal sequences of the molybdopterin oxidoreductases shows that three of the genes include likely TAT signal sequences. Moorella thermoacetica encodes TatA and TatC proteins (Moth_1278 and Moth_1279), but does not have a tatB gene. This is also true of Bacillus subtilis, which uses a system composed of $A$ and $C$ subunits (Jongbloed et al., 2004). Two genes similar to tor $D$, flanking a gene cluster that encodes three molybdopterin-containing oxidoreductases, two of which have TAT sequences, might be chaperones for the TAT system (Hatzixanthis et al., 2005; Genest et al., 2006).

In addition to the molybdopterin oxidoreductases, M. thermoacetica has additional genes that could be involved in growth on electron acceptors other than $\mathrm{CO}_{2}$, e.g. sulfite and nitrate (Table S5). One gene cluster has three genes that have about $80 \%$ sequence identity with the dissimilatory sulfite reductase $(d s r A B)$ and the gene $d s r D$, of unknown function, from Desulfotomaculum thermocisternum (Larsen et al., 1999). Directly upstream from these genes are a gene similar to the membrane component of E. coli nitrate reductase, narl, a gene similar to nrfD which is a transmembrane component of $E$. coli nitrite reductase, two predicted iron-sulfur containing proteins, and a cytochrome $c$. The dissimilatory sulfite reductase does not have any likely transmembrane regions, but the additional genes might serve to connect the reductase to a membrane-bound respiratory pathway. One other possible sulfite reductase gene cluster, Moth_1629-32, has $d s r A B$ genes, and two genes similar to $d s r C$ from A. fulgidus, whose function is not fully resolved. The genes in this cluster have only about $30 \%$ sequence identity to the most closely related genes in GenBank. The four genes in this second cluster have no predicted transmembrane domains.

\section{Expanded gene groups in M. thermoacetica based on comparative COG analysis}

The $M$. thermoacetica genome was compared with those of $T$. ethanolicus and $T$. tengcongensis to obtain insights into $M$. thermoacetica's wide metabolic range. We analysed the placement of $M$. thermoacetica, T. ethanolicus and $T$. tengcongensis genes in COGs to identify functions with increased representation in $M$. thermoacetica. Table S6 shows some of the COGs with increased representation along with the number of genes belonging to each COG. The largest expansions in M. thermoacetica, relative to the other Thermoanaerobacteriaceae genome sequences, are in COGs that could encode proteins involved in electron transfer to or from growth substrates, including molybdopterin oxidoreductases in the dimethylsulfoxide reductase family detailed above, and in the xanthine dehydrogenase family (Kisker et al., 1999), with subunits in COGs 1529, 1319 and 2080. The xanthine dehydrogenase subunits might be part of a pathway of purine degradation including amidohydrolase genes (COG0402), which are adjacent to two of the xanthine dehydrogenase genes. The COGs containing heterodisulfide reductase and sulfite reductase discussed above are absent from T. ethanolicus and T. tengcongensis, 
except for one subunit A homologue in T. ethanolicus. Moorella thermoacetica has 13 genes representing two COGs of proteins that are likely to contain iron-sulfur clusters, and that seem to have diverse functions in the $M$. thermoacetica genome. COG0247 is part of the possible glycolate oxidase proposed above as the homologue of $E$. coli glcF. COG0247 sequences are also adjacent to a heterodisulfide reductase A gene (Moth_1453) that is unlinked to any other heterodisulfide reductase subunits, and to one of the sulfite reductase gene clusters. A gene encoding a COG0437 protein is part of the same sulfite reductase gene cluster, and other COG0437 proteins are predicted to be encoded by genes adjacent to many of the molybdopterin oxidoreductase genes, and are found in two gene clusters with aldehyde-ferredoxin oxidoreductases (COG2414).

Moorella thermoacetica has four genes in COG1251, which contains $\mathrm{NAD}(\mathrm{P}) \mathrm{H}$-dependent nitrite reductase subunits similar to $E$. coli's cytoplasmic nirB. However, $M$. thermoacetica lacks the gene encoding the other subunit of the enzyme found in E. coli, nirD (COG2146). One COG1251 gene is within an apparent glutamate synthase operon (Moth_1289-94), while another is adjacent to a gene cluster containing COG0437, an aldehydeferredoxin oxidoreductase and a gene similar to $E$. colis MoaD, which is involved in molybdopterin biosynthesis (Moth_0721-24). The third COG1251 gene is in a gene cluster with COG0243 and the lone heterodisulfide reductase A gene (Moth_1452-54), while the fourth is next to a hypothetical protein sequence of unknown function.

Another large expansion is in COGs related to methyl transfer reactions. Included in these COGs are the methyltransferase of the Wood-Ljungdahl pathway (Fig. 2) and other genes that could feed methyl groups into this pathway, including $m t v A$ and $m t v C$ homologues, and COG0407 which includes mtvB (Table 6). Four COG0407 genes are positioned close to $m t v A$ and $m t v C$ homologues, and four are adjacent to two putative sugar phosphate permeases that are members of family 1 of the major facilitator superfamily, in COG2271, which is also expanded in $M$. thermoacetica.

Another expanded COG group contains components of ABC-type nitrate/sulfonate/bicarbonate transport systems. These are represented by four gene clusters, each containing an ATPase, a permease component and a periplasmic component. Each of the Thermoanaerobacter species encodes one complete transporter from these three COGs.

\section{Genes involved in cofactor synthesis}

The only vitamin required for $M$. thermoacetica's growth is nicotinic acid, a precursor of NAD and NADP (Lundie and Drake, 1984). Moorella thermoacetica appears to have genes encoding the phosphoribosyl transferase (Moth_1836), adenylyltransferase (Moth_0564) and glutamine-dependent NAD synthetase (Moth_0553) needed for conversion of nicotinic acid to NAD (Moth_1836, Moth_0564 and Moth_0553).

As only one vitamin is required for growth, genes encoding pathways for synthesis of all other cofactors should be present in the genome. Two metabolic routes for the synthesis of tetrahydrofolate are the de novo synthesis pathway (Fig. S5) and a salvage pathway. In E. coli, the de novo synthesis pathway requires the activities of the proteins encoded by the genes folE, fol $B$, folK, folP, fol $C$ and folA to produce the final product, 6-(S)-tetrahydrofolate. Moorella thermoacetica has no folA gene, but the isoenzyme encoded by $y d g B$ (folM) is present in three copies. The activities of two other enzymes from this pathway have been measured in E. coli, but the genes that encode the proteins are not yet known, so no comparison is possible with the $M$. thermoacetica genome. The functions of the tetrahydrofolate salvage pathway in M. thermoacetica, which regenerates tetrahydrofolate from 5- or 10-formyl-tetrahydrofolate could be accomplished by methylene-tetrahydrofolate dehydrogenase/methenyltetrahydrofolate cyclohydrolase of the Wood-Ljungdahl pathway (Moth_1516) and Moth_2045, a phosphoribosylglycinamide formyl-transferase.

Moorella thermoacetica has a complete pathway of cobalamin biosynthesis. Cobalamin is a central cofactor in the autotrophic metabolism of $M$. thermoacetica, linking the methyl and carbonyl branches of the Wood-Ljungdahl pathway, with the methylated corrinoid iron-sulfur protein serving as a substrate of the acetyl-CoA synthase reaction. Moorella thermoacetica contains over 20 different types of cobalamin or precursors that total 300$700 \mathrm{nmol} \mathrm{g}^{-1}$ of cells (Ljungdahl et al., 1966). The levels of corrinoids and their structural diversity in anaerobic bacteria have been reviewed (Stupperich et al., 1990). Both the anaerobic branch of corrin ring synthesis and the common branch of the adenosyl-cobalamin pathway are intact. Although several genes in the aerobic pathway of corrin ring synthesis are also present in the $M$. thermoacetica genome, these genes are not specific to the aerobic route and genes that are unique to the aerobic pathway are absent in $M$. thermoacetica. Almost all of the cobalamin biosynthesis genes are located within a single gene cluster (Moth_1087-1104) in the $M$. thermoacetica genome. ABC transporters, which are encoded by cbiM, $N, Q$ and $O$, mediate high affinity transport of cobalt ions for $\mathrm{B}_{12}$ synthesis. Three gene clusters (Moth_1219-1222, Moth_1861-1863 and Moth_2427-2429) have combinations of cbiM, N, $Q$ and $O$ genes.

As expected from the numbers of DMSO reductase and xanthine oxidase family proteins encoded in the 
M. thermoacetica genome, this organism has genes that could be used to synthesize molybdenum cofactors (Fig. S6). Most of these were found based on their homology to E. coli and Arabidopsis thaliana genes (Schwartz, 2005). Moorella thermoacetica has homologues of all E. coli molybdenum cofactor synthesis genes except for moaE, which encodes the large subunit of molybdopterin synthase. Some M. thermoacetica homologues of mogA, moaC, moaA and moeA are found in one cluster of genes (Moth_2132-2137), along with a gene belonging to pfam03473, which is a family of predicted sulfur-carrying proteins which are sometimes associated with molybdenum cofactor sulfurase domains, as in molybdopterin synthase. Another gene cluster (Moth_1819-1824) has a gene homologous to mobB from E. coli, the function of which is not known, another moeA homologue, a gene that matches the C-terminal half of $m o b A$, and three subunits of a possible $A B C$-type molybdate transporter, homologous to $\bmod A B C$ from $E$. coli.

\section{Transporter genes}

Two hundred and ten transport genes, constituting approximately one hundred and thirty transport systems, were identified in the $M$. thermoacetica genome (Table S7). These include six $\alpha$-helical membrane channels for the transport of anions, cations and small solutes. The genome encodes 61 secondary permeases, which transport a variety of substrates that include amino acids, sugars, anions, cations, nucleotides and toxic drugs. Sixteen belong to the Major Facilitator Superfamily (MFS), two are RND-type transporters, six are DMT-type drug and metabolite transporters and three belong to the MOP superfamily. One hundred three proteins encoded in the genome constitute approximately $35 \mathrm{ABC}$-type transport systems, which are predicted to transport anions, cations, peptides, amino acids, vitamins, heavy metal ions and toxic drugs. The genome also encodes four polypeptides that form a single fructose-type sugar-transporting phosphotransferase system. Three cation-transporting P-type ATPases were also recognized in the genome. Approximately 19 putative transporters with unknown substrates were also identified in the genome.

\section{Motility genes}

Moorella thermoacetica is not motile, although stains show peritrichous flagella (Fontaine et al., 1942). Thirty-five $M$. thermoacetica genes encode proteins forming entire components and substructure of flagella, such as motor, switch complex, basal body and filament (Fig. S7). These proteins fall into at least six groups: hookassociated proteins (FlgK and FlgL), basal and hook proteins (FlgE), capping proteins (FliD), biosynthesis secretory proteins (FlhA, FlhB, FliF, FliH and Flil), flagella formation proteins, motor proteins (FliG and FliM) and basal proteins (FlgC and FlgB). However, genes encoding the accessory flagellar assembly proteins, FlgA, FlhC, FlhD and FliT, could not be identified in the M. thermoacetica genome. The organization of the genes for the general component of the flagellar proteins export apparatus appears to be similar to that found in Bacillus subtilis (Macnab, 2004). A similar gene cluster exists in Thermoanaerobacter tengcongensis, which also does not have functional flagella in cultures, but seems to have many of the genes for flagellar assembly and chemotaxis (Xue et al., 2001; Bao et al., 2002). From the genome annotation, $M$. thermoacetica also has an elaborate cascade of chemotaxis genes, including six chemoreceptors, together with a complete set of flagellar genes, most located within three large clusters of about 70 genes (Moth_0740-7, Moth_0764-91, Moth_0797-Moth_0805). The only exception is CheZ, which is not found in the Moorella or Thermoanaerobacter tengcongensis genomes. CheZ, a protein known to accelerate dephosphorylation of the response regulator $\mathrm{CheY}$, has only been found in a few non-thermophilic Gram-negative bacteria, such as E. coli (Blattner et al., 1997), Pseudomonas aeruginosa (Stover et al. 2000) and Vibrio cholerae (Heidelberg et al. 2000), and it is not essential for flagellar motility and chemotaxis (Scharf et al., 1998). The presence of genes involved in flagellar structure and movement in both non-motile $M$. thermoacetica and T. tengcongensis suggests either that they might be inactive or activated only under certain environmental conditions or that they have lost function only recently before divergence of these two species. In the $T$. tengcongensis proteomics study, two key gene products of the flagella formation, motor proteins (FliG and FliM) and basal proteins (FlgC and FlgB) were not detected, supporting the suspicion that incomplete gene expression may cause the absence of flagella in the cultured cells (Wang et al., 2004).

\section{Discussion}

This paper describes the first genomic sequence of an acetogen. The genomic results clearly indicate that the trait of acetogenesis is a metabolic, not a phylogenetic trait. To identify a set of genes that are responsible for the acetogenic lifestyle, the $M$. thermoacetica genome was compared with those of all Firmicutes, Chlorflexi and Deltaproteobacteria sequences available at IMG. Surprisingly, the only $M$. thermoacetica genes with homologues in the other bacterial genomes that also have acetyl-CoA synthase, but lack homologues in any of the genome sequences without acetyl-CoA synthase, are acetyl-CoA synthase itself and the two subunits of the corrinoid ironsulfur protein (CFeSP). While the genes encoding the 
$\mathrm{H}_{4}$ folate-dependent enzymes in the Eastern part of the pathway are scattered around the genome, the 'core set of Wood-Ljungdahl genes' (acsA-acsE) in the Western part of the pathway are colocalized. Being required for general C-1 metabolism in all organisms, the Eastern branch genes are ubiquitous; thus, we suggest that acquisition of the acs gene cluster by horizontal transfer might be sufficient for gaining the ability to utilize the WoodLjungdahl pathway. For some organisms, this would confer the ability to grow as a homoacetogen; for others (sulfate reducers and aceticlastic methanogens), the ability to oxidize acetate. Acquisition of the core WoodLjungdahl genes would allow a wide variety of organisms, including archaea and a broad range of bacterial phyla (Firmicutes, Chlorflexi and Deltaproteobacteria), to fix CO and $\mathrm{CO}_{2}$ by the reductive acetyl-CoA pathway. The simple strategy of the Wood-Ljungdahl pathway of successively joining two one-carbon compounds to make a two-carbon compound has been envisioned to be the earliest form of metabolism (Martin and Russell, 2007).

The genomic analysis also revealed a second CODH (Moth_1972), which has not been characterized biochemically. Other genomes contain multiple CODHs, like C. hydrogenoformans, which contains five CODHs (Wu et al., 2005). The only genes that could be identified to encode a phosphotransacetylase in $M$. thermoacetica (Moth_1181 and Moth_0864), are homologous to the recently characterized novel enzyme from Salmonella enterica called pduL (Liu et al., 2007); thus, it is important to test this function by performing biochemical assays on these putative phosphotransacetylases.

Perhaps not surprisingly, given the metabolic diversity of acetogenic microbes, the largest COG expansions in M. thermoacetica, relative to the other Thermoanaerobacteriaceae genome sequences, involve electron transfer proteins. How electron donors and acceptors interact with respiratory pathways in $M$. thermoacetica also remains an open question. Although the enzymes in the WoodLjungdahl pathway have been characterized, it has been unclear how acetogens gain energy, as there is no net ATP synthesis by substrate-level phosphorylation. Homologues of NADH dehydrogenase I (Table 3 ) and archaeal heterodisulfide reductase (Table 5) are present in the genome. Other genes identified that may play important roles in electron transfer linked proton translocation are Moth_2184-90, with significant homology to the genes encoding the subunits of $E$. colis hydrogenase 4 (Table 4), which has been proposed to have proton translocating ability (Andrews et al., 1997). These various sets of genes could encode partial or complete membranebound complexes that would function in anaerobic respiration by generating a transmembrane proton gradient for use by the $F_{1} F_{0} A T P$ synthase (Moth_2377-84). Localization of genes encoding homologues of heterodisulfide reductase (Moth_1194-Moth_1196), a hydrogenase (Moth_1193) and 5,10-methylene- $\mathrm{H}_{4}$ folate reductase (Moth_1191) near the acs gene cluster are consistent with a suggestion that the reductase and a hydrogenase might link to CODH to generate a proton motive force, driving anaerobic respiration in acetogens (Thauer et al., 1977).

Moorella thermoacetica contains eight genes encoding molybdopterin-containing proteins, that are likely to encode the reductases that allow growth on nitrate (Fröstl et al., 1996), dimethylsulfoxide and thiosulfate (Beaty and Ljungdahl, 1991), as well as reductases for other electron acceptors not yet identified (Table 7). These molybdopterin-dependent proteins would then link to the membrane-bound respiratory systems described in the previous paragraph. The genomic information described here should help identify the specific membraneassociated proteins that are recruited to allow growth on these various electron acceptors. It is likely that these electron transfer components are differentially expressed under different growth conditions and the large number of them might be part of $M$. thermoacetica's strategy for fine-tuning its growth to specific environmental conditions. The presence of so many different sets of genes that are likely to encode proteins involved in energy generation by electron and proton transport (for example, the presence of three heterodisulfide reductase gene clusters) could be part of this strategy. That cytochrome $b$, which is found in membranes of $M$. thermoacetica cells grown using the Wood-Ljungdahl pathway, is downregulated in cells grown on nitrate (Arendsen et al., 1999) indicates that the respiratory pathway used in connection with the WoodLjungdahl pathway is different than the one used during growth on nitrate, at least in some components.

Other expanded gene groups that were identified in $M$. thermoacetica include methyltransferases, which are required for growth on various methyl group donors (methanol, methoxylated aromatics), and ABC-type nitrate/sulfonate/bicarbonate transport systems, which also perhaps reflect the ability of acetogens to grow on a wide variety of substrates. Methyltransferase genes that link to the Wood-Ljungdahl pathway (besides acsCDE) include mtaABC (Moth_1208-1209) encoding the methanol:methyl- $\mathrm{H}_{4}$ folate methyltransferase system, mtvABC (Moth_1316-1318 and Moth_0385-0387), which transfers the methyl group of methoxylated aromatic compounds to $\mathrm{H}_{4}$ folate, and several other methyltransferase genes whose specific biochemical functions have not been assigned.

We were unable to predict the pathways by which $M$. thermoacetica metabolizes the two-carbon organic acids oxalate, glyoxylate and glycolate (Seifritz et al., 1999). The most reduced compound among these is glycolate, which is oxidized to glyoxylate in E. coli (Pellicer et al., 1996) by an FMN- and $\mathrm{H}_{2} \mathrm{O}_{2}$-dependent glycolate 
oxidase, which is encoded by the glcDEF genes that are homologous to genes located in two gene clusters in M. thermoacetica. However, it seems unlikely that the anaerobe $M$. thermoacetica uses an oxidase mechanism. Homologues of malate synthase (GlcB), which catalyses formation of malate from glyoxylate and acetyl-CoA, or glyoxylate carboligase (converts $2 \mathrm{~mol}$ of glyoxylate to form tartronate semialdehyde), were not found in $M$. thermoacetica, which is consistent with the lack of enzymatic activities for these proteins in extracts of cells grown on glyoxylate (Seifritz et al., 2002). Perhaps malate is formed from glyoxylate and acetyl-CoA by a glyoxylate reductase homologue (Moth_ 1954). Homologues of proteins in the pathway of oxalate metabolism in Oxalobacter formigenes, which begins with oxalyl-CoA formation, were also missing from the $M$. thermoacetica genome. A hint for the oxalate metabolic pathway is that a $33 \mathrm{kDa}$ protein is induced when $M$. thermoacetica is grown on oxalate (Daniel and Drake, 1993); however, no sequence information for this protein has yet been described. Postgenomic studies will likely uncover how acetogens use the $\mathrm{g} / \mathrm{c}$ gene cluster and/or other genes to metabolize oxalate, glyoxylate and glycolate under anaerobic conditions. Identifying the mechanism of growth on oxalate should be particularly interesting, because during oxalatedependent growth, $M$. thermoacetica uses $\mathrm{CO}_{2}$ preferentially over nitrate as a terminal electron acceptor. Oxalate is the only substrate for $M$. thermoacetica for which this preference has been found.

Knowing the complete genome sequence of $M$. thermoacetica will be a valuable tool to help understand the growth of this organism and the acetogenic lifestyle. The genome sequence enables protein expression studies and microarrays, which should address important questions arising from annotation of this genome sequence. For example, growth of $M$. thermoacetica on oxalate and glyoxylate, followed by 2D electrophoresis analysis of proteins could uncover shifts in protein expression that would uncover what pathways are used. Protein and gene expression studies, on cells grown on different electron acceptors, could help identify the pathways of anaerobic respiration in $M$. thermoacetica. Such experiments will uncover how electrons are passed from electron donor to electron acceptor during growth, and how M. thermoacetica switches among different donors and acceptors, depending on what substrates are available in its environment. Similar studies may reveal how $M$. thermoacetica grows in different environments and in different ecological settings; for example, how its metabolism and gene expression patterns change when an acetogen is part of a microbial community or in coculture with a methanogen or sulfate reducer that can act as a $\mathrm{H}_{2}$ sink. In turn, proteomic and microarray studies should help us improve the annotation of the genome, by allowing us to identify specific biochemical functions and metabolic roles for genes of unknown or partially known function.

\section{Experimental procedures}

\section{DNA extraction and purification}

Moorella thermoacetica cells were grown at $55^{\circ} \mathrm{C}$ in the presence of $100 \mathrm{mM}$ glucose $\left(18 \mathrm{~g} \mathrm{l}^{-1}\right)$ under $100 \% \mathrm{CO}_{2}$ in the medium described by Ljungdahl and Andreesen (Ljungdahl and Andreesen, 1978), containing yeast extract and tryptone. Another sample of DNA was prepared from cells grown at $58^{\circ} \mathrm{C}$ on $200 \mathrm{mM}$ methanol under $100 \% \mathrm{CO}_{2}$ in Drake's medium (Seifritz et al., 1993). The DNA was then isolated according to the procedure of Marmur (Marmur, 1961) and stored frozen at $-20^{\circ} \mathrm{C}$ in $10 \mathrm{mM} \mathrm{Tris} / \mathrm{HCl}, \mathrm{pH} 8.0$ and $1 \mathrm{mM}$ EDTA at a concentration of $438 \mu \mathrm{g} \mathrm{ml}^{-1}$.

\section{Genome sequencing}

The genome of $M$. thermoacetica was sequenced at the Joint Genome Institute (JGI) using a combination of 3, 6, 7 and $37 \mathrm{~kb}$ (fosmid) DNA libraries. All general aspects of library construction and sequencing performed at the JGI can be found at http://www.jgi.doe.gov/. Draft assemblies were based on 41897 total reads. All four libraries provided 18x coverage of the genome. The Phred/Phrap/Consed software package (http://www.phrap.com) was used for sequence assembly and quality assessment (Han and Chain, 2006). After the shotgun stage, reads were assembled with parallel phrap (High Performance Software, LLC). Possible misassemblies were corrected with Dupfinisher (Abraham et al., 2006) or transposon bombing of bridging clones (Epicentre Biotechnologies, Madison, WI). Gaps between contigs were closed by editing in Consed, custom primer walk and PCR amplification (Roche Applied Science, Indianapolis, IN). A total of 3345 additional reactions were necessary to close gaps and to raise the quality of the finished sequence. The completed genome sequence of $M$. thermoacetica contains 45242 reads, achieving an average of eightfold sequence coverage per base with an error rate less than 1 in 100000 .

\section{Annotation}

Automated gene modelling was completed by combining results from Critica, Generation and Glimmer modelling packages, and comparing the translations to GenBank's nonredundant database using the basic local alignment search tool for proteins (BLASTP). Predicted coding sequences were subjected to manual analysis using JGl's gene models quality assessment pipeline. The predicted functions were further analysed by using the Integrated Microbial Genomes (IMG) annotation pipeline (http://img.jgi.doe.gov; Markowitz et al., 2006).

\section{Comparative analysis}

Comparative analysis of $M$. thermoacetica ATCC 39073, Thermoanaerobacter tengcongensis MB4 and Thermoa- 
naerobacter ethanolicus 39E was performed by using a set of tools available at IMG. Unique and orthologous $M$. thermoacetica genes were identified by using BLASTP (cut-off scores of $E<10^{-2}$ and $20 \%$ identity and reciprocal hits with cut-offs of $E<10^{-5}$ and $30 \%$ respectively). The transporter database (TCDB; http://www.tcdb.org; Saier et al., 2006) was used to identify all the transporters in the genome of $M$. thermoacetica. Twin arginine transport signal sequences were predicted by the TatP server at http://www. cbs.dtu.dk/services/TatP/ (Bendtsen et al., 2005). Metabolic pathways were constructed with reference to MetaCyc (Caspi et al., 2006) and PubMed. Identification numbers given in the text for individual genes are IMG locus tag numbers, which can be used to search for genes at the Integrated Microbial Genomes website.

\section{Phylogenetic trees}

The phylogenetic tree was made using prealigned 16S rRNA sequences derived from the Ribosomal Database site (http:// rdp.cme.msu.edu/index.jsp) (Cole et al., 2007). Manual alignment adjustments were made as needed with the assistance of the BioEdit multiple alignment tool of Hall (http://www.mbio. ncsu.edu/BioEdit/bioedit.html). The refined multiple alignment was used as input for generation of a phylogenetic tree using the program package version 3.1 (Kumar et al., 2004). The Neighbor Joining (Saitou and Nei, 1987), Minimum Evolution (Nei et al., 1998; Takahashi and Nei, 2000), UPGMA (Nei and Kumar, 2000) and Maximum Parsimony (Fitch, 1971) methods with the default settings were employed to obtain phylogenetic trees. Both the distance- and character-based trees yielded similar clusters and arrangements of taxa.

\section{Nucleotide sequence accession number}

The sequence data described here have been deposited in GenBank under Accession No. CP000232.

\section{Acknowledgements}

We are grateful to the DOE Joint Genome Institute for selecting $M$. thermoacetica for sequencing and to many people at JGI who were involved in the sequencing effort. The work was supported by a grant from NIH (GM39451, S.W.R.). We thank Thomas Morton for extracting one of the DNA samples used in these studies.

\section{References}

Abraham, L.O., Li, Y., and Zamble, D.B. (2006) The metaland DNA-binding activities of Helicobacter pylori NikR. $J$ Inorg Biochem 100: 1005-1014.

Adrian, N.R., and Arnett, C.M. (2004) Anaerobic biodegradation of hexahydro-1,3,5-trinitro-1,3,5-triazine (RDX) by Acetobacterium malicum strain HAAP-1 Isolated from a methanogenic mixed culture. Curr Microbiol 48: 332-340.

Andreesen, J.R., and Ljungdahl, L.G. (1973) Formate dehydrogenase of Clostridium thermoaceticum: incorporation of selenium-75, and the effects of selenite, molybdate, and tungstate on the enzyme. J Bacteriology 116: 867-873.
Andreesen, J.R., Schaupp, A., Neurauter, C., Brown, A., and Ljungdahl, L.G. (1973) Fermentation of glucose, fructose, and xylose by Clostridium thermoaceticum: effect of metals on growth yield, enzymes, and the synthesis of acetate from $\mathrm{CO}_{2}$. J Bacteriology 114: 743-751.

Andrews, S.C., Berks, B.C., McClay, J., Ambler, A., Quail, M.A., Golby, P., and Guest, J.R. (1997) A 12-cistron Escherichia coli operon (hyf) encoding a putative protontranslocating formate hydrogenlyase system. Microbiology 143: 3633-3647.

Arendsen, A.F., Soliman, M.Q., and Ragsdale, S.W. (1999) Nitrate-dependent regulation of acetate biosynthesis and nitrate respiration by Clostridium thermoaceticum. J Bacteriol 181: 1489-1495.

Balch, W.E., Schoberth, S., Tanner, R.S., and Wolfe, R.S. (1977) Acetobacterium, a new genus of hydrogenoxidizing, carbon-dioxide-reducing, anaerobic bacteria. Int J Syst Bacteriol 27: 355-361.

Bao, Q., Tian, Y., Li, W., Xu, Z., Xuan, Z., Hu, S., et al. (2002) A complete sequence of the Thermoanaerobacter tengcongensis genome. Genome Res 12: 689-700.

Barker, H.A., and Kamen, M.D. (1945) Carbon dioxide utilization in the synthesis of acetic acid by Clostridium thermoaceticum. Proc Natl Acad Sci 31: 219-225.

Beaty, S.P., and Ljungdahl, L.G. (1991) Growth of Clostridium thermoaceticum on methanol, ethanol, propanol, and butanol in medium containing either thiosulfate or dimethylsulfoxide. In Abstracts of the Annual Meeting of the American Society for Microbiology, abstr. K-131, p. 236. Washington, DC: American Society for Microbiology.

Bendtsen, J., Nielsen, H., Widdick, D., Palmer, T., and Brunak, S. (2005) Prediction of twin-arginine signal peptides. BMC Bioinformatics 6: 167.

Blattner, F.R., Plunkett, G. III, Bloch, C.A., Perna, N.T., Burland, V., Riley, M., et al. (1997) The complete genome sequence of Escherichia coli K-12. Science 277: 14531462.

Blokesch, M., Paschos, A., Bauer, A., Reissmann, S., Drapal, N., and Böck, A. (2004) Analysis of the transcarbamoylation-dehydration reaction catalyzed by the hydrogenase maturation proteins HypF and HypE. Eur $J$ Biochem 271: 3428-3436.

Boynton, Z.L., Bennett, G.N., and Rudolph, F.B. (1996) Cloning, sequencing, and expression of genes encoding phosphotransacetylase and acetate kinase from Clostridium acetobutylicum ATCC 824. Appl Environ Microbiol 62: 2758-2766.

Braun, M., Mayer, F., and Gottschalk, G. (1981) Clostridium aceticum (Wieringa), a microorganism producing acetic acid from molecular hydrogen and carbon dioxide. Arch Microbiol 128: 288-293.

Breznak, J.A. (1994) Acetogenesis from carbon dioxide in termite guts. In Acetogenesis. Drake, H.L. (ed.). New York, USA: Chapman \& Hall, pp. 303-330.

Caspi, R., Foerster, H., Fulcher, C.A., Hopkinson, R., Ingraham, J., Kaipa, P., et al. (2006) MetaCyc: a multiorganism database of metabolic pathways and enzymes. Nucleic Acids Res 34: D511-D516.

Chassard, C., and Bernalier-Donadille, A. (2006) $\mathrm{H}_{2}$ and acetate transfers during xylan fermentation between a butyrate-producing xylanolytic species and hydro- 
genotrophic microorganisms from the human gut. FEMS Microbiol Lett 254: 116-122.

Clark, J.E., and Ljungdahl, L.G. (1982) Purification and properties of 5,10-methenyltetrahydrofolate cyclohydrolase. $J$ Biol Chem 257: 3833-3836.

Clark, J.E., and Ljungdahl, L.G. (1984) Purification and properties of 5,10-methylenetetrahydrofolate reductase, an iron-sulfur flavoprotein from clostridium formicoaceticum. J Biol Chem 259: 10845-10889.

Cole, J.R., Chai, B., Farris, R., Wang, Q., Kulam-Syedmohideen, A.S., McGarrell, D., et al. (2007) The ribosomal database project (RDP-II): introducing myRDP space and quality controlled public data. Nucleic Acids Res 35: D169D172.

Collins, M., Lawson, P., Willems, A., Cordoba, J., FernandezGarayzabal, J., Garcia, P., et al. (1994) The phylogeny of the genus Clostridium: proposal of five new genera and eleven new species combinations. Int J Syst Bacteriol 44: 812-826.

Daniel, S.L., and Drake, H.L. (1993) Oxalate- and glyoxylatedependent growth and acetogenesis by Clostridium thermoaceticum. Appl Environ Microbiol 59: 3062-3069.

Das, A., and Ljungdahl, L. (1997) Composition and primary structure of the F1F0 ATP synthase from the obligately anaerobic bacterium Clostridium thermoaceticum. J Bacteriol 179: 3746-3755.

Das, A., Hugenholtz, J., Van Halbeek, H., and Ljungdahl, L.G. (1989) Structure and function of a menaquinone involved in electron transport in membranes of Clostridium thermoautotrophicum and Clostridium thermoaceticum. J Bacteriol 171: $5823-5829$.

Das, A., Fu, Z.-Q., Tempel, W., Liu, Z.-J., Chang, J., Chen, L., et al. (2007) Characterization of a corrinoid protein involved in the $\mathrm{C} 1$ metabolism of strict anaerobic bacterium Moorella thermoacetica. Proteins: Struct. Funct. Bioinf. 67: 167-176.

Deppenmeier, U. (2004) The membrane-bound electron transport system of Methanosarcina species. J Bioenerg Biomembr 36: 55-64.

Drake, H.L. (1982) Demonstration of hydrogenase in extracts of the homoacetate-fermenting bacterium Clostridium thermoaceticum. J Bacteriol 150: 702-709.

Drake, H.L., and Daniel, S.L. (1997) Acetogenic bacteria: what are the in situ consequences of their diverse metabolic versatilities? BioFactors 6: 13-24.

Drake, H.L., Daniel, S.L., Matthies, C., and Küsel, K. (1994) Acetogenesis, acetogenic bacteria, and the acetyl-CoA pathway: past and current perspectives. In Acetogenesis. Drake, H.L. (ed). New York, USA: Chapman \& Hall, pp. 3-60.

Drake, H.L., Hu, S.I., and Wood, H.G. (1981) Purification of five components from Clostridium thermoaceticum which catalyze synthesis of acetate from pyruvate and methyltetrahydrofolate. Properties of phosphotransacetylase. J Biol Chem 256: 11137-11144.

Drake, H.L., Kusel, K., and Matthies, C. (2002) Ecological consequences of the phylogenetic and physiological diversities of acetogens. Antonie Van Leeuwenhoek 81: 203213.

Ferry, J.G. (1999) Enzymology of one-carbon metabolism in methanogenic pathways. FEMS Microbiol Rev 23: 13-38.
Fischer, F., Lieske, R., and Winzer, K. (1932) Biologische gasreaktionen. II. Gber die bildung von essigs ure bei der biologischen umsetzung von kohlenoxyd und kohlens ure mit wasserstoff zu methan. Biochem Z 245: 2-12.

Fitch, W.M. (1971) Towards defining the course of evolution: minimum change for a specific tree topology. Syst Zool 20: 406-416.

Fontaine, F.E., Peterson, W.H., McCoy, E., Johnson, M.J., and Ritter, G.J. (1942) A new type of glucose fermentation by Clostridium thermoaceticum n. sp. J Bacteriol 43: 701715.

Fox, J.D., He, Y., Shelver, D., Roberts, G.P., and Ludden, P.W. (1996) Characterization of the region encoding the CO-induced hydrogenase of Rhodospirillum rubrum. $J$ Bacteriol 178: 6200-6208.

Fröstl, J.M., Seifritz, C., and Drake, H.L. (1996) Effect of nitrate on the autotrophic metabolism of the acetogens Clostridium thermoautotrophicum and Clostridium thermoaceticum. J Bacteriol 187: 4597-4603.

Furdui, C., and Ragsdale, S.W. (2002) The roles of coenzyme a in the pyruvate: ferredoxin oxidoreductase reaction mechanism: rate enhancement of electron transfer from a radical intermediate to an iron-sulfur cluster. Biochemistry 41: 9921-9937.

Gencic, S., and Grahame, D.A. (2003) Nickel in subunit beta of the acetyl-CoA decarbonylase/synthase multienzyme complex in methanogens: catalytic properties and evidence for a binuclear Ni-Ni site. J Biol Chem 278: 61016110.

Genest, O., Seduk, F., Ilbert, M., Méjean, V., and lobbi-Nivol, C. (2006) Signal peptide protection by specific chaperone. Biochem Biophys Res Comms 339: 991-995.

Gill, S.R., Pop, M., Deboy, R.T., Eckburg, P.B., Turnbaugh, P.J., Samuel, B.S., et al. (2006) Metagenomic analysis of the human distal gut microbiome. Science 312: 13551359.

Gon, S., Giudici-Orticoni, M.-T., Mejean, V., and lobbi-Nivol, C. (2001) Electron transfer and binding of the c-type cytochrome TorC to the trimethylamine $\mathrm{N}$-oxide reductase in Escherichia coli. J Biol Chem 276: 11545-11551.

Gößner, A., Devereux, R., Ohnemüller, N., Acker, G., Stackebrandt, E., and Drake, H.L. (1999) Thermicanus aegyptius gen. nov., sp. nov., isolated from oxic soil, a fermentative microaerophile that grows commensally with the thermophilic acetogen Moorella thermoacetica. Appl Environ Microbiol 65: 5124-5133.

Gottwald, M., Andreesen, J.R., LeGall, J., and Ljungdahl, L.G. (1975) Presence of cytochrome and menaquinone in Clostridium formicoaceticum and Clostridium thermoaceticum. J Bacteriol 122: 325-328.

Greening, R.C., and Leedle, J.A.Z. (1989) Enrichment and isolation of Acetitomaculum ruminis, gen. nov., sp. nov.: acetogenic bacteria from the bovine rumen. Arch Microbiol 151: 399-406.

Han, C.S., and Chain, P. (2006) Finishing repeat regions automatically with Dupfinisher. In Proceeding of the 2006 International Conference on Bioinformatics and Computational Biology. Valafar, H. (ed). Las Vegas, USA: CSREA Press, pp. 141-146.

Harmsen, H., Van Kuijk, B., Plugge, C., Akkermans, A., De Vos, W., and Stams, A. (1998) Syntrophobacter fumaroxi- 
dans sp. nov., a syntrophic propionate-degrading sulfatereducing bacterium. Int J Syst Bacteriol 48: 1383-1387.

Hatzixanthis, K., Clarke, T.A., Oubrie, A., Richardson, D.J., Turner, R.J., and Sargent, F. (2005) Signal peptidechaperone interactions on the twin-arginine protein transport pathway. Proc Natl Acad Sci 102: 8460-8465.

Hedderich, R. (2004) Energy-converting [NiFe] hydrogenases from archaea and extremophiles: ancestors of complex I. J Bioenerg Biomembr 36: 65-75.

Heidelberg, J.F., Elsen, J.A., Nelson, W.C., Clayton, R.A., Gwinn, M.L., Dodson, R.J., et al. (2000) DNA sequence of both chromosomes of the cholera pathogen Vibrio cholerae. Nature 406: 477-484.

Heise, R., Muller, V., and Gottschalk, G. (1989) Sodium dependence of acetate formation by the acetogenic bacterium Acetobacterium woodii. J Bacteriol 171: 5473-5478.

Himes, R.H., and Wilder, T. (1968) Formyltetrahydrofolate synthetase. Effect of $\mathrm{pH}$ and temperature on the reaction. Arch Biochem Biophys 124: 230.

Hugenholtz, J., Ivey, D.M., and Ljungdahl, L.G. (1987) Carbon monoxide-driven electron transport in Clostridium thermoautotrophicum membranes. J Bacteriol 169: 58455847.

Jeon, W.B., Cheng, J., and Ludden, P.W. (2001) Purification and characterization of membrane-associated CooC protein and its functional role in the insertion of nickel into carbon monoxide dehydrogenase from Rhodospirillum rubrum. J Biol Chem 42: 38602-38609.

Jongbloed, J.D.H., Grieger, U., Antelmann, H., Hecker, M., Nijland, R., Bron, S., and van Dijl, J.M. (2004) Two minimal Tat translocases in Bacillus. Mol Microbiol 54: 13191325 .

Kerby, R., and Zeikus, J.G. (1983) Growth of Clostridium thermoaceticum on $\mathrm{H}_{2} / \mathrm{CO}_{2}$ or $\mathrm{CO}$ as energy source. Curr Microbiol 8: 27-30.

Kisker, C., Schindelin, H., Baas, D., Rétey, J., Merkenstock, R.U., and Kroneck, P.M.H. (1999) A structural comparison of molybdenum cofactor-containing enzymes. FEMS Microbiol Rev 22: 503-521.

Kumar, S., Tamura, K., and Nei, M. (2004) MEGA3: integrated software for molecular evolutionary genetics analysis and sequence alignment. Brief Bioinform 5: 150-163.

Kusel, K., Wagner, C., and Drake, H.L. (1999) Enumeration and metabolic product profiles of the anaerobic microflora in the mineral soil and litter of a beech forest. FEMS Microbiol Ecol 29: 91-103.

Ladapo, J., and Whitman, W. (1990) Method for isolation of auxotrophs in the methanogenic archaebacteria: role of the acetyl-CoA pathway of autotrophic $\mathrm{CO}_{2}$ fixation in Methanococcus maripaludis. PNAS 87: 5598-5602.

Larsen, Ø., Lien, T., and Birkeland, N.-K. (1999) Dissimilatory sulfite reductase from Archaeoglobus profundus and Desulfotomaculum thermocisternum: phylogenetic and structural implications from gene sequences. Extremophiles 3: 63-70.

Leadbetter, J.R., Schmidt, T.M., Graber, J.R., and Breznak, J.A. (1999) Acetogenesis from $\mathrm{H}_{2}$ plus $\mathrm{CO}_{2}$ by spirochetes from termite guts. Science 283: 686-689.

Le Van T.D., Robinson, J.A., Ralph, J., Greening, R.C., Smolenski, W.J., et al. (1998) Assessment of reductive acetogenesis with indigenous ruminal bacterium popula- tions and Acetitomaculum ruminis. Appl Environ Microbiol 64: 3429-3436.

Li, L.-F., Ljungdahl, L., and Wood, H.G. (1966) Properties of nicotinamide adenine dinucleotide phosphate-dependent formate dehydrogenase from Clostridium thermoaceticum. $J$ Bacteriol 92: 405-412.

Liesack, W., Bak, F., Kreft, J.U., and Stackebrandt, E. (1994) Holophaga foetida gen. nov., sp. nov., a new, homoacetogenic bacterium degrading methoxylated aromatic compounds. Arch Microbiol 162: 85-90.

Liu, S., and Suflita, J.M. (1993) $\mathrm{H}_{2}-\mathrm{CO}_{2}$-dependent anaerobic O-demethylation activity in subsurface sediments and by an isolated bacterium. Appl Environ Microbiol 59: 13251331.

Liu, Y., Leal, N.A., Sampson, E.M., Johnson, C.L.V., Havemann, G.D., and Bobik, T.A. (2007) PduL Is an evolutionarily distinct phosphotransacylase involved in B12-dependent 1,2-propanediol degradation by Salmonella enterica serovar Typhimurium LT2. J Bacteriol 189: 1589-1596.

Ljungdahl, L.G. (1986) The autotrophic pathway of acetate synthesis in acetogenic bacteria. Annu Rev Microbiol 40: 415-450.

Ljungdahl, L.G. (1994) The acetyl-CoA pathway and the chemiosmotic generation of ATP during acetogenesis. In Acetogenesis. Drake, H.L. (ed.). New York, USA: Chapman \& Hall, pp. 63-87.

Ljungdahl, L.G., and Andreesen, J.R. (1975) Tungsten, a component of active formate dehydrogenase from Clostridium thermoacetium. FEBS Lett 54: 279-282.

Ljungdahl, L.G., and Andreesen, J.R. (1978) Formate dehydrogenase, a selenium-tungsten enzyme from Clostridium thermoaceticum. Methods Enzymol 53: 360-372.

Ljungdahl, L.G., Irion, E., and Wood, H.G. (1966) Role of corrinoids in the total synthesis of acetate from $\mathrm{CO}_{2}$ by Clostridium thermoaceticum. Fed Proc 25: 1642.

Lovell, C.R., Przybyla, A., and Ljungdahl, L.G. (1988) Cloning and expression in Escherichia coli of the Clostridium thermoaceticum gene encoding thermostable formyltetrahydrofolate synthetase. Arch Microbiol 149: 280-285.

Lovell, C.R., Przybyla, A., and Ljungdahl, L.G. (1990) Primary structure of the thermostable formyltetrahydrofolate synthetase from Clostridium thermoaceticum. Biochemistry 29: 5687-5694.

Lundie, L.L., Jr and Drake, H.L. (1984) Development of a minimally defined medium for the acetogen Clostridium thermoaceticum. J Bacteriol 159: 700-703.

Lutz, S., Jacobi, A., Schlensog, V., Böhm, R., Sawers, G., and Böck, A. (1991) Molecular characteriyation of an operon (hyp) necessary for the activity of the three hydrogenase isoenzymes in Escherichia coli. Mol Microbiol 5: 123-135.

Macbeth, T.W., Cummings, D.E., Spring, S., Petzke, L.M., and Sorenson, K.S., Jr (2004) Molecular characterization of a dechlorinating community resulting from in situ biostimulation in a trichloroethene-contaminated deep, fractured basalt aquifer and comparison to a derivative laboratory culture. Appl Environ Microbiol 70: 7329-7341.

McGuire, J.J., and Rabinowitz, J.C. (1978) Studies on the mechanism of formyltetrahydrofolate synthetase. The Peptococcus aerogenes enzyme. J Biol Chem 253: 1079. 
Mackie, R.I., and Bryant, M.P. (1994) Acetogenesis and the rumen: syntrophic relationships. In Acetogenesis. Drake, H.L. (ed). New York, USA: Chapman \& Hall, pp. 331-364.

Macnab, R.M. (2004) Type III flagellar protein export and flagellar assembly. Biochim Biophys Acta 1694: 207217.

Markowitz, V.M., Korzeniewski, F., Palaniappan, K., Szeto, E., Werner, G., Padki, A., et al. (2006) The integrated microbial genomes (IMG) system. Nucleic Acids Res 34: D344-D348.

Marmur, J. (1961) A procedure for the isolation of deoxyribonucleic acid from microorganisms. J Mol Biol 3: 208-218.

Martin, W., and Russell, M.J. (2007) On the origin of biochemistry at an alkaline hydrothermal vent. Philos Trans $R$ Soc Lond B Biol Sci 362: 1887-1925.

Maupin-Furlow, J.A., and Ferry, J.G. (1996) Analysis of the $\mathrm{CO}$ dehydrogenase/acetyl-coenzyme A synthase operon of Methanosarcina thermophila. J Bacteriol 178: 6849-6856.

Meuer, J., Bartoschek, S., Koch, J., Künkel, A., and Hedderich, R. (1999) Purification and catalyc properties of Ech hydrogenase from Methanosarcina barkeri. Eur $J$ Biochem 265: 235-335.

Moore, M.R., O'Brien, W.E., and Ljungdahl, L.G. (1974) Purification and characterization of nicotinamide adenine dinucleotide-dependent methylenetetrahydrofolate dehydrogenase from Clostridium formicoaceticum. J Biol Chem 249: 5250-5253.

Muller, V. (2003) Energy conservation in acetogenic bacteria. Appl Environ Microbiol 69: 6345-6353.

Naidu, D., and Ragsdale, S.W. (2001) Characterization of a three-component vanillate O-demethylase from Moorella thermoacetica. J Bacteriol 183: 3276-3281.

Nei, M., and Kumar, S. (2000) Molecular Evolution and Phylogenetics. New York, USA: Oxford University Press.

Nei, M., Kumar, S., and Takahashi, K. (1998) The optimization principle in phylogenetic analysis tends to give incorrect topologies when the number of nucleotides or amino acids used is small. Proc Natl Acad Sci USA 95: 1239012397.

Neumann, A., Engelmann, T., Schmitz, R., Greiser, Y., Orthaus, A., and Diekert, G. (2004) Phenyl methyl ethers: novel electron donors for respiratory growth of Desulfitobacterium hafniense and Desulfitobacterium sp. strain PCE-S. Arch Microbiol 181: 245-249.

Nonaka, H., Keresztes, G., Shinoda, Y., Ikenaga, Y., Abe, M., Naito, K., et al. (2006) Complete genome sequence of the dehalorespiring bacterium desulfitobacterium hafniense Y51 and comparison with Dehalococcoides ethenogenes 195. J Bacteriol 188: 2262-2274.

Núñez, F.M., Pellicer, M.-T., Badía, J., Aguilar, J., and Baldomà, L. (2001) The gene yghK linked to the glc operon of Escherichia coli encodes a permease for glycolate that is structurally and functionally similar to L-lactate permease. Microbiology 147: 1069-1077.

O'Brien, W.E., Brewer, J.M., and Ljungdahl, L.G. (1975) Chemical, physical and enzymatic comparisons of formyltetrahydrofolate synthetases from thermo- and mesophilic clostridia. In Proceedings of the International Symposium on Enzymes and Proteins from Thermophilic Microorganisms, Structure and Functions. Zuber, H. (ed). Basel, Switzerland: Birkhauser-Verlag, p. 249.
Odelson, D.A., and Breznak, J.A. (1983) Volatile fatty acid production by the hindgut microbiota of xylophagous termites. Appl Environ Microbiol 45: 1602-1613.

Ohshima, T., Nunoura-Kominato, N., Kudome, T., and Sakuraba, H. (2001) A novel hyperthermophilic archaeal glyoxylate reductase from Thermococcus litoralis. Characterization, gene cloning, nucleotide sequence and expression in Escherichia coli. Eur J Biochem 268: 4740-4747.

Ollivier, B., Caumette, P., Garcia, J.-L., and Mah, R.A. (1994) Anaerobic bacteria from hypersaline environments. Microbiol Rev 58: 27-38.

Park, E.Y., Clark, J.E., DerVartanian, D.V., and Ljungdahl, L.G. (1991) 5,10-methylenetetrahydrofolate reductases: iron-sulfur-zinc flavoproteins of two acetogenic clostridia. In Chemistry and Biochemistry of Flavoenzymes. Miller, F. (ed). Boca Raton, FI, USA: CRC Press, pp. 389-400.

Pellicer, M.-T., Badía, J., Aguilar, J., and Baldomà, L. (1996) glc locus of Escherichia coli: characterization of genes encoding the subunits of glycolate oxidase and the $g / c$ regulator protein. J Bacteriol 178: 2051-2059.

Pester, M., and Brune, A. (2007) Hydrogen is the central free intermediate during lignocellulose degradation by termite gut symbionts. ISME J 1: 551-565.

Peters, V., and Conrad, R. (1995) Methanogenic and other strictly anaerobic bacteria in desert soil and other oxic soils. Appl Environ Microbiol 61: 1673-1676.

Ragsdale, S.W. (1997) The Eastern and Western branches of the Wood/Ljungdahl pathway: how the East and West were won. Biofactors 6: 3-11.

Ragsdale, S.W., and Ljungdahl, L.G. (1984) Purification and properties of NAD-dependent 5,10methylenetetrahydrofolate dehydrogenase from Acetobacterium woodii. J Biol Chem 259: 3499-3503.

Roberts, D.L., James-Hagstrom, J.E., Garvin, D.K., Gorst, C.M., Runquist, J.A., Baur, J.R., et al. (1989) Cloning and expression of the gene cluster encoding key proteins involved in acetyl-CoA synthesis in Clostridium thermoaceticum: CO dehydrogenase, the corrinoid/FeS protein, and methyltransferase. Proc Natl Acad Sci 86: 32-36.

Rosencrantz, D., Rainey, F.A., and Janssen, P.H. (1999) Culturable populations of Sporomusa spp. and Desulfovibrio spp. in the anoxic bulk soil of flooded rice microcosms. Appl Environ Microbiol 65: 3526-3533.

Saier, M.H. Jr, Tran, C.V., and Barabote, R.D. (2006) TCDB: the transporter classification database for membrane transport protein analyses and information. Nucleic Acids Res 34: D181-D186.

Saitou, N., and Nei, M. (1987) The neighbor-joining method: a new method for reconstructing phylogenetic trees. Mol Biol Evol 4: 406-425.

Salmassi, T.M., and Leadbetter, J.R. (2003) Analysis of genes of tetrahydrofolate-dependent metabolism from cultivated spirochaetes and the gut community of the termite Zootermopsis angusticollis. Microbiology 149: 2529-2537 (cover illustration).

Sazanov, L.A., and Hinchliffe, P. (2006) Structure of the hydrophilic domain of respiratory complex I from thermus thermophilus. Science 311: 1430-1436.

Scharf, B.E., Fahrner, K.A., and Berg, H.C. (1998) CheZ has no effect on flagellar motors activated by CheY13DK106YW. J Bacteriol 180: 5123-5128. 
Schauder, R., Preuß, A., Jetten, M.S., and Fuchs, G. (1988) Oxidative and reductive acetyl $\mathrm{CoA} /$ carbon monoxide dehydrogenase pathway in Desulfobacterium autotrophicum. Arch Microbiol 151: 84-89.

Schaupp, A., and Ljungdahl, L.G. (1974) Purification and properties of acetate kinase from Clostridium thermoaceticum. Arch Microbiol 100: 121-129.

Schink, B. (1997) Energetics of syntrophic cooperation in methanogenic degradation. Microbiol Mol Biol Rev 61: 262-280.

Schink, B., Thiemann, V., Laue, H., and Friedrich, M.W. (2002) Desulfotignum phosphitoxidans sp. nov., a new marine sulfate reducer that oxidizes phosphite to phosphate. Arch Microbiol 177: 381-391.

Schwartz, G. (2005) Molybdenum cofactor biosynthesis and deficiency. Cell Mol Life Sci 62: 2792-2910.

Seifritz, C., Daniel, S.L., Gößner, A., and Drake, H.L. (1993) Nitrate as a preferred electron sink for the acetogen Clostridium thermoaceticum. J Bacteriol 175: 8008-8013.

Seifritz, C., Fröstl, J.M., Drake, H.L., and Daniel, S.L. (1999) Glycolate as a metabolic substrate for the acetogen Moorella thermoacetica. FEMS Microbiol Lett 170: 399405.

Seifritz, C., Fröstl, J.M., Drake, H.L., and Daniel, S.L. (2002) Influence of nitrate on oxalate- and glyoxylate-dependent growth and acetogenesis by Moorella thermoacetica. Arch Microbiol 178: 457-464.

Seifritz, C., Drake, H.L., and Daniel, S.L. (2003) Nitrite as an energy-conserving electron sink for the acetogenic bacterium Moorella thermoacetica. Curr Microbiol 46: 329-333.

Seshadri, R., Adrian, L., Fouts, D.E., Eisen, J.A., Phillippy, A.M., Methe, B.A., et al. (2005) Genome sequence of the PCE-dechlorinating bacterium Dehalococcoides ethenogenes. Science 307: 105-108.

Setzke, E., Hedderich, R., Heiden, S., and Thauer, R. (1994) $\mathrm{H}_{2}$ : heterodisulfide oxidoreductase complex from Methanobacterium thermoautotrophicum. Composition properties. Eur J Biochem 220: 139-148.

Shannon, K.W., and Rabinowitz, J.C. (1988) Isolation and characterization of the Saccharomyces cerevisiae MIS1 gene encoding mitochondrial $\mathrm{C}_{1}$-tetrahydrofolate synthase. J Biol Chem 263: 7717.

So, C.M., Phelps, C.D., and Young, L.Y. (2003) Anaerobic transformation of alkanes to fatty acids by a sulfatereducing bacterium, strain Hxd3. Appl Environ Microbiol 69: 3892-3900.

Soboh, B., Linder, D., and Hedderich, R. (2002) Purification and catalytic properties of a CO-oxidizing: $\mathrm{H}_{2}$-evolving enzyme complex from Carboxydothermus hydrogenoformans. Eur J Biochem 269: 5712-5721.

Spormann, A.M., and Thauer, R.K. (1988) Anaerobic acetate oxidation to $\mathrm{CO}_{2}$ by Desulfotomaculum acetoxidans demonstration of enzymes required for the operation of an oxidative acetyl-CoA/carbon monoxide dehydrogenase pathway. Arch Microbiol 150: 374-380.

Staben, C., and Rabinowitz, J.C. (1986) Nucleotide sequence of the Saccharomyces cerevisiae ADE3 gene encoding $\mathrm{C}_{1}$-tetrahydrofolate synthase. J Biol Chem 261: 2986.

Stover, C.K., Pham, X.Q., Erwin, A.L., Mizoguchi, S.D., Warrener, P., Hickey, M.J., et al. (2000) Complete genome sequence of Pseudomonas aeruginosa PAO1, an opportunistic pathogen. Nature 406: 959-964.

Strous, M., Pelletier, E., Mangenot, S., Rattei, T., Lehner, A., Taylor, M.W., et al. (2006) Deciphering the evolution and metabolism of an anammox bacterium from a community genome. Nature 440: 790-794.

Stupperich, E., Hammel, K.E., Fuchs, G., and Thauer, R.K. (1983) Carbon monoxide fixation into the carboxyl group of acetyl coenzyme A during autotrophic growth of Methanobacterium. FEBS Lett 152: 21-23.

Stupperich, E., Eisinger, H.-J., and Schurr, S. (1990) Corrinoids in anaerobic bacteria. FEMS Microbiol. Lett 87: 355-360.

Sun, A.Y., Ljungdahl, L., and Wood, H.G. (1969) Total Synthesis of acetate from $\mathrm{CO}_{2}$ II. Purification and properties of formyltetrahydrofolate synthetase from Clostridium thermoaceticum. J Bacteriol 98: 842-844.

Takahashi, K., and Nei, M. (2000) Efficiencies of fast algorithms of phylogenetic inference under the criteria of maximum parsimony, minimum evolution, and maximum likelihood when a large number of sequences are used. Mol Biol Evol 17: 1251-1258.

Thauer, R.K., Jungermann, K., and Decker, K. (1977) Energy conservation in chemotrophic anaerobic bacteria. Bacteriol Rev 41: 100-180.

Tholen, A., and Brune, A. (1999) Localization and in situ activities of homoacetogenic bacteria in the highly compartmentalized hindgut of soil-feeding higher termites (Cubitermes spp.). Appl Environ Microbiol 65: 44974505.

Wang, J., Xue, Y., Feng, X., Li, X., Wang, H., Li, W., et al. (2004) An analysis of the proteomic profile for Thermoanaerobacter tengcongensis under optimal culture conditions. Proteomics 4: 136-150.

Warnecke, F., Luginbuhl, P., Ivanova, N., Ghassemian, M., Richardson, T.H., Stege, J.T., et al. (2007) Metagenomic and functional analysis of hindgut microbiota of a woodfeeding higher termite. Nature 450: 560-565.

Wiegel, J., and Ljungdahl, L.G. (1981) Thermoanaerobacter ethanolicus gen. nov., spec. nov., a new, extreme thermophilic, anaerobic bacterium. Arch Microbiol 128: 343-348.

Wieringa, K.T. (1936) Over het verdwinjhnen van waterstof en koolzuur onder anaerobe voorwaarden. Antonie Van Leeuwenhoek 3: 263-273.

Wieringa, K.T. (1940) The formation of acetic acid from carbon dioxide and hydrogen by anaerobic spore-forming bacteria. Antonie Van Leeuwenhoek 6: 251-262.

Wood, H.G. (1952) Fermentation of $3,4-C^{14}-$ and $1-C^{14}$. labeled glucose by Clostridium thermoaceticum. J Biolog Chem 199: 579-583.

Wood, H.G., and Ljungdahl, L.G. (1991) Autotrophic character of the acetogenic bacteria. In Variation in Autotrophic Life. Shively, J.M., and Barton, L.L. (eds). New York, USA: Academic Press, pp. 201-250.

Wu, M., Ren, Q., Durkin, A.S., Daugherty, S.C., Brinkac, L.M., Dodson, R.J., et al. (2005) Life in hot carbon monoxide: the complete genome sequence of Carboxydothermus hydrogenoformans Z-2901. PLoS Genetics 1: e65.

Xue, Y., Xu, Y., Liu, Y., Ma, Y., and Zhou, P. (2001) Thermoanaerobacter tengcongensis sp. nov., a novel anaerobic, saccharolytic, thermophilic bacterium isolated 
from a hot spring in Tengcong, China. Int J Syst Evol Microbiol 51: 1335-1341.

Yamamoto, I., Saiki, T., Liu, S., and Ljungdahl, L. (1983) Purification and properties of NADP-dependent formate dehydrogenase from Clostridium thermoaceticum, a tungsten-selenium-iron protein. J Biol Chem 258: 18261832.

Ye, Q., Roh, Y., Carroll, S.L., Blair, B., Zhou, J., Zhang, C.L., and Fields, M.W. (2004) Alkaline anaerobic respiration. Isolation and characterization of a novel alkaliphilic and metal-reducing bacterium. Appl Environ Microbiol 70: 5595-5602.

\section{Supplementary material}

The following supplementary material is available for this article online:

Table S1. Pseudogenes found in the M. thermoacetica genome.

Table S2. Parameters for BLAST alignments of some $M$. thermoacetica sequences mentioned in the text with GenBank sequences.

Table S3. Genes belonging to alcohol and aldehyde dehydrogenase COGs and pfams.

Table S4. Five M. thermoacetica gene clusters made up of COGs found in pyruvate:ferredoxin oxidoreductase.

Table S5. Dissimilatory sulfite reductase gene cluster.

Table S6. COGs with greater representation in the $M$. thermoacetica genome than in genomes of two closely related bacteria.

Table S7. Transporters encoded in the genome of M. thermoacetica.

Fig. S1. Circular representations of the genome of M. thermoacetica ATCC 39073. The outermost two circles indicate start sites of genes and assigned function (coloured by COG categories). Circle 1 consists of forward-strand gene products. Circle 2 consists of reverse-strand gene products. Colours represent the following functional categories: amino acid biosynthesis, cyan; biosynthesis of cofactors, brown; cell envelope, light gray; cellular processes, light blue; central intermediary metabolism, dark salmon; energy metabolism, green; fatty acid and phospholipid metabolism, orange; other categories, salmon; protein fate, dark gray; purines, pyrimidines, nucleosides, and nucleotides, light green; regulatory functions, light salmon; replication, blue; transcription and translation, magenta; transport and binding proteins, yellow; unassigned, black; unknown function, red; circle 3, RNA genes (tRNAs green, sRNAs red); circle 4, pseudogenes, circle 5, IS elements; circle 6, G+C content; circle 7, GC skew $[(\mathrm{G}-\mathrm{C} / \mathrm{G}+\mathrm{C})$, khaki indicates values $>1$, purple $<1]$.

Fig. S2. Pathway proposed for metabolism of xylose. Locus tags for genes encoding individual steps are shown.

Fig. S3. Pathway proposed for metabolism of glucose and fructose. Locus tags for genes encoding individual steps are shown.

Fig. S4. Pyruvate from sugar metabolism provides electrons and carbon for acetate synthesis by the Wood-Ljungdahl pathway.

Fig. S5. Tetrahydrofolate synthesis. Moorella thermoacetica genes which could be involved in synthesis of tetrahydrofolate from guanosine triphosphate and chorismate. The sequences of genes encoding enzymes which catalyse the transformations of 7,8-dihydroneopterin $3^{\prime}$-triphosphate to dihydroneopterin phosphate and dihydroneopterin phosphate to dihydroneopterin are not known.

Fig. S6. Synthesis of molybdenum cofactor and bismolybdopterin guanine dinucleotide cofactor from guanine triphosphate. No M. thermoacetica genes were found with homology to the large subunit of molybdopterin synthase, MoaE.

Fig. S7. Components of the bacterial flagellar proteins in M. thermoacetica. The figure was derived from the KEGG web server (Kanehisa et al., 2006; http://www.genome.jp/ $\mathrm{keg} /$ ). The gene IDs that correspond to the labelled flagellar proteins are as follows: FlgB (Moth_0768), FlgC (Moth_0769), FlgD (Moth_0777), FlgE (Moth_0779), FlgG (Moth_0764), FlgK (Moth_0746), FlgL (Moth_0747), FlgL (Moth_0760), FlgM (Moth_0744), FlgN (Moth_0745), FlhA (Moth_0790), FlhB (Moth_0789), FliD (Moth_0765), FliE (Moth_0770), FliF (Moth_0771), FliG (Moth_0772), FliH (Moth_0773), Flil (Moth_0774), FliJ (Moth_0775), FliK (Moth_0776), FliM (Moth_0804), FliN (Moth_0784), FliO (Moth_0785), FliP (Moth_0786), FliQ (Moth_0787), FliR (Moth_0788), FliS (Moth_0766). Genes encoding FlgA, FlhC, FlhD, FliT proteins could not be identified in the M. thermoacetica genome. However, additional putative flagellar genes with unknown functions are encoded in the genome, such as Moth_0780 (FlbD), Moth_0783 (FliL), Moth_0791 (FlhF), Moth_0797 (FlgE-like), Moth_0798 (FlgElike).

This material is available as part of the online article from http://www.blackwell-synergy.com

Please note: Blackwell Publishing is not responsible for the content or functionality of any supplementary materials supplied by the authors. Any queries (other than missing material) should be directed to the corresponding author for the article. 